\title{
Biomedical applications of Raman and infrared spectroscopy to diagnose tissues
}

\author{
C. Krafft* and V. Sergo \\ Department of Materials and Natural Resources, University of Trieste, Via Valerio 2, 34127 Trieste, \\ Italy
}

\begin{abstract}
The objective of the article is to review biomedical applications which became possible after the development of sensitive and high throughput Raman and Fourier transform infrared spectrometers in the past decade. Technical aspects of the instrumentation are briefly described. Then the broad range of vibrational spectroscopic applications with the focus on imaging and fiber-optical methods are discussed to study mineralized tissue (bone, teeth), skin, brain, the gastrointestinal tract (mouth, pharynx, esophagus, colon), breast, arteries, cartilage, cervix uteri, the urinary tract (prostate, bladder), lung, ocular tissue, liver, heart and spleen. Experimental studies are summarized demonstrating the possibilities and prospects of these methods in various fields of biodiagnostics to detect and characterize diseases, tumors and other pathologies.
\end{abstract}

Keywords: Raman spectroscopy, infrared spectroscopy, tissue diagnostics, cancer, tumor

List of abbreviations: IR, infrared; ATR, attenuated total reflection; FT, Fourier transform; FPA, focal plane array; NIR, near infrared; CCD, charge coupled device; SCC, squamous cell carcinoma.

\section{Introduction}

Infrared (IR) and Raman spectroscopy have recently been applied to address various biomedical issues. The basis for these applications is that IR and Raman spectroscopy are vibrational spectroscopic techniques capable of providing details of the chemical composition and molecular structures in cells and tissues. In principle, diseases and other pathological anomalies lead to chemical and structural changes on the molecular level which also change the vibrational spectra and which can be used as sensitive, phenotypic markers of the disease. As these spectral changes are very specific and unique, they are also called fingerprint. The advantages of the methods include that they are non-destructive and do not require extrinsic contrast-enhancing agents. Early reports in the literature regarding the utility of IR and Raman spectroscopy to biomedical problems were based on macroscopic acquisition of spectral data only at single points which required an a priori knowledge of the location or a pre-selection of the probed position. Since the inhomogeneous nature of tissue was not considered in these early studies, an accurate correlation between the histopathology of the sampled area and the corresponding spectra was not possible. Therefore, many of the early results were spurious and they will not be presented here. Considerable progress was made in the past ten years because high throughput and more sensitive instruments became available for Raman and IR microspectroscopic imaging. They enable to microscopically collect larger number of spectra from larger sample populations in less time, improving statistical significance and spatial specificity. Simultaneously, fiber-optical probes have been developed for in vivo applications.

\footnotetext{
*Corresponding author: Tel.: +39 040 5583447; Fax: +39040 572044; E-mail ckrafft@ units.it.
} 
These methodologies open wide perspectives for routine use in the clinical environment combining the capability of vibrational spectroscopy for molecular analysis with the power for immediate and effective visualization.

The IR absorption spectrum provides essentially the same type of information as the Raman scattering spectrum, namely the energies of molecular vibrations. However, the two methods differ fundamentally in their physical mechanism, and each has specific advantages for biological applications. Instrumentation is typically less complex for IR (absorption of radiation) than for Raman (light scattering); also IR data collection is generally faster, often leading to signal to noise ratios superior to those obtainable by modern Raman spectrometers. After the introduction of powerful imaging spectrometers, IR spectroscopy offers in particular opportunities for the development of visualization tools which aid the pathologist in assessing tissue specimens. Conversely, water is a notoriously strong IRabsorbing medium, and aqueous systems can only be investigated by IR spectroscopy if samples of few micrometer thickness are prepared for transmission measurements or if attenuated total reflection (ATR) measurements are performed. In contrast, water interferes only feebly with Raman spectra of species in aqueous solutions and hydrated solids. Therefore, biological material like tissue and cells can generally be investigated more favorably by Raman than by IR spectroscopy.

Despite technological improvements in standard white light endoscopy, the ability to visually detect micro-morphological and/or biochemical changes remains limited. Among several optical methods currently under investigation for improvement of in vivo endoscopic applications, such as elastic light scattering, optical coherence tomography and fluorescence spectroscopy, Raman spectroscopy offers the advantage of high molecular specificity. In vivo diagnostic tools are much needed in many fields of medicine such as the guidance of surgical interventions to delineate lesions margins or to replace random biopsies of suspicious tissues by targeted biopsies which, in turn, would reduce unnecessary tissue excisions, pathology costs and biopsy-associated risks. Furthermore, these developments in tissue spectroscopy might provide on-line monitoring the effect of therapies and using the feedback to individualize drug or radiation treatment.

In part 2 of this article, sample preparation and instrumentation are presented to obtain vibrational spectroscopic images and to couple the spectrometers with fiber-optic probes. In part 3, we review biomedical applications of Raman and IR spectroscopy focusing on imaging and fiber-optics to detect and characterize diseases, tumors and other pathologies. Imaging of single cells, the numerous algorithms for data analyses and investigation of biofluids are not discussed in detail. The reader is referred to other reviews [1-5] or specialized papers in these fields [6-8]. Finally, some conclusions are drawn in part 4.

\section{Samples and instrumentation}

\subsection{Sample preparation}

In general, both IR and Raman spectroscopy require minimal or no sample preparation. Spectroscopic data can be collected in transmission or in reflection mode. For IR spectroscopy in transmission mode, samples have to be sufficient thin and the substrates have to be transparent to the wavelength range of the probing radiation in the mid-IR range from 400 to $4000 \mathrm{~cm}^{-1}$. In order to fulfill these conditions, sections of typically 5 to $20 \mu \mathrm{m}$ are cut from frozen tissues or from tissues embedded in support medium (e.g. paraffin for soft tissues) using a microtome and are then mounted on substrates made from materials such as $\mathrm{CaF}_{2}, \mathrm{BaF}_{2}$ or $\mathrm{ZnSe}$. However, these sample substrates are expensive and may have 
undesirable mechanical and optical properties. Therefore, glass slides coated with a metal layer are also used as substrates for thin tissue sections which are then probed in "IR reflection-absorption" mode. Tissue sections are usually dried before IR experiments as water strongly absorbs IR radiation. The process of paraffin-embedding requires sample dehydration and fixation before embedding and removal of the support medium by solvents after sectioning. Therefore, a disadvantage of the process is that the chemical composition of the sample might be altered, e.g. hydrophobic constituents, such as lipids, will be removed by solvent treatment as well. IR spectra can also be collected in back scattered geometry using the ATR mode. Here, samples are in contact to an ATR crystal made from IR-transparent material. However, penetration of IR radiation into the samples is restricted to few micrometers.

Raman spectra are usually collected in reflection mode. Thin sections are mounted on substrates with low background signals. Using near infrared (NIR) light at $785 \mathrm{~nm}$ for excitation, $\mathrm{CaF}_{2}$ or $\mathrm{BaF}_{2}$ slides have a particularly low background and they allow also collecting IR spectra. Tissues can be studied in its native state under in vivo conditions by Raman spectroscopy. Light penetration depends on factors such as excitation wavelength, excitation intensity, sample composition and optical geometry.

Due to the non-destructivity of the methods, tissue sections can be stained by hematoxylin and eosin or by more specific stains after data acquisition, thus allowing visual imaging and pathological examination. For a pre-assessment before spectroscopic data acquisition, a parallel section can be prepared on standard glass slides and stained.

\subsection{FTIR spectroscopy}

The interferometric principle of Fourier transform IR (FTIR) spectrometers include the multiplex, the throughput and the wavenumber accuracy advantage named after Felgett, Jacquinot and Connes, respectively. The light path in a typical FTIR spectrometer in schematically depicted in Fig. 1A and compared to the light path of a dispersive Raman spectrometer in Fig. 1B. The basic approach in implementing an interferometer to obtain two-dimensional, laterally resolved IR spectra requires the detected radiation to define a specific region of a sample. This lateral localization is accomplished in two optical configurations. Mapping techniques restrict radiation at the sample plane by an aperture. Imaging techniques segment radiation at the detection plane by IR-sensitive multi-channel detectors, termed focal plane array (FPA) detectors. Fig. 2 shows a schematic representation of both data collection modes. A methodological extension includes three-dimensional FTIR imaging which analyzes multiple tissue sections by FTIR imaging and reconstruct them by image processing techniques $[9,10]$.

\subsubsection{FTIR mapping}

The mapping approach defines a grid on the sample area of interest and IR spectra are then acquired sequentially from each grid point using a single-element detector and a motorized sample stage (Fig. 2A). The lateral resolution depends on the size of the aperture and the step size which is usually set to the same value as the aperture. To achieve high lateral resolutions near the diffraction limit of IR radiation, the aperture has to be set to $10 \times 10 \mu \mathrm{m}^{2}$ or smaller which severely restricts the IR flux that reaches the detector, leading to long acquisition times or low signal to noise ratios in conventional FTIR spectrometers with a thermal source for illumination. In order to improve the sensitivity using small apertures, IR radiation from synchrotron sources is used which offers a brightness advantage of factor 100-1000. A number of IR synchrotron research facilities have been established in the past years and their number will even increase in the next years. Chemical imaging of biological tissue with synchrotron IR radiation has been reviewed recently [11]. 
(A)

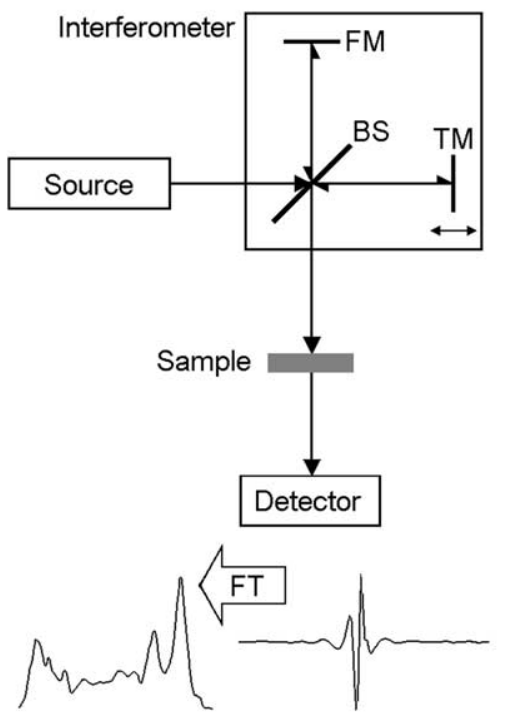

(B)

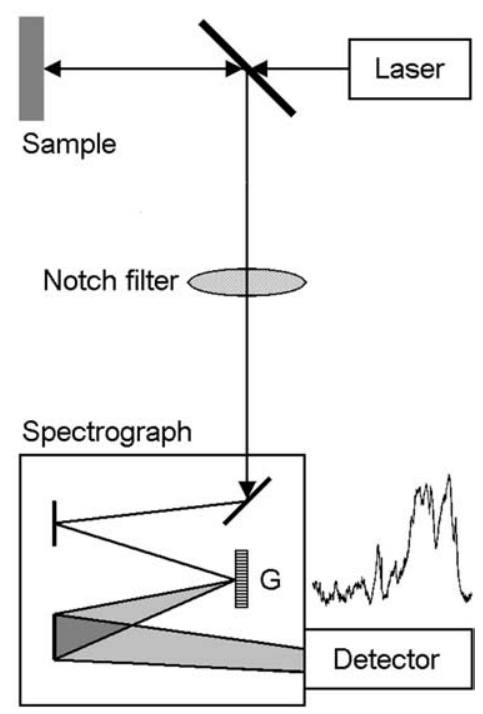

Fig. 1. Schematic light path in a Fourier transform infrared spectrometer (A): Radiation from the IR source is guided to the beam splitter BS of the interferometer. After reflecting from the fixed mirror FM and the translating mirror TM, both portions of the radiation interfere and the transmitted fraction is detected. Fourier transformation FT of the interferogram results in the IR spectrum. Schematic light path in a dispersive Raman spectrometer (B): The laser is focused on the sample, backscattered light is collected, the elastically scattered portion is suppressed by a Notch filter, the inelastically scattered portion is guided to the spectrograph, dispersed by grating $\mathrm{G}$ and detected.

(A)

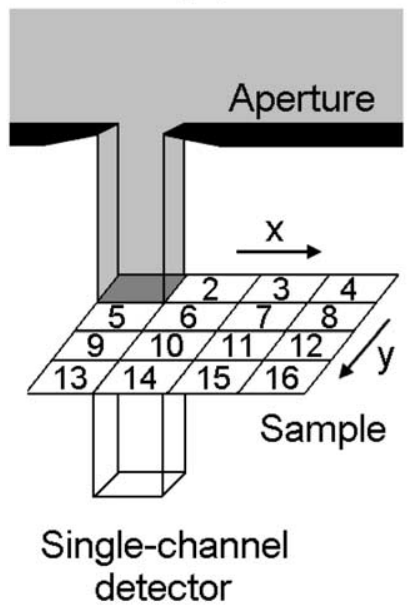

(B)

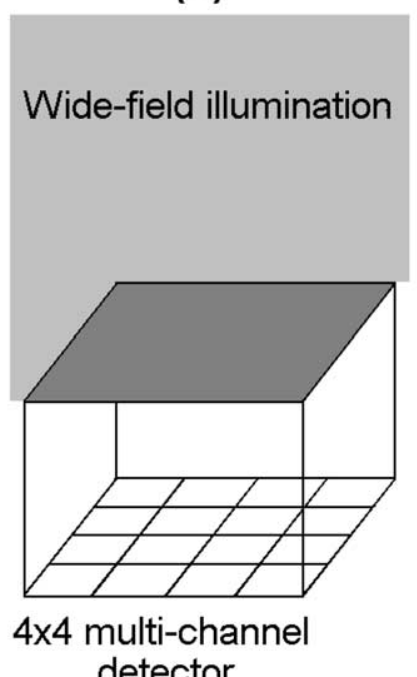

Fig. 2. Scheme of the mapping mode with an aperture, a movable stage and a single-channel detector representing the serial imaging approach (A), and scheme of the imaging mode with wide-field illumination of the sample and multi-channel detection representing the parallel imaging approach (B). 


\subsubsection{FTIR imaging}

In the imaging approach the entire field of view is illuminated and imaged on an array of IR-sensitive detection elements (Fig. 2B). Each individual detector in the array is capable of simultaneously collecting data from a specific sample region within the field of view without using apertures. Commonly used array detectors comprise $64 \times 64$ elements, hence they permit collecting of 4096 IR spectra per image. By coupling the multi-channel detection of FPA detectors with the spectral multiplexing advantage of FTIR interferometry, an entire sample field of view can be spectroscopically imaged in a time comparable to acquiring conventionally a single spectrum. The lateral resolution is determined by the magnification of the optical system and the size of the detector elements and reaches values near the diffraction limit. Issues of lateral resolution in FTIR imaging have recently been reviewed [12]. In general, while FTIR imaging with FPA detection significantly reduce accumulation times, the lateral resolution is not as good as a confocal FTIR microscope using apertures before and after the sample, because an FTIR imaging instrument cannot operate in a confocal arrangement. Application of ATR-FTIR imaging to biomedical samples can achieve a lateral resolution of 3-4 $\mu \mathrm{m}$ [13].

\subsubsection{IR fiber-optical probes}

IR radiation can be guided out of the FTIR spectrometer through an optical fiber to an ATR probe from which FTIR spectra are recorded. Then the IR radiation is guided back to the spectrometer through another optical fiber. Silver halide waveguides were developed for bioanalytical applications to transmit IR radiation [14]. Few investigations were reported using IR fiber-optic probes in tissue studies [1518]. Due to the very short penetration of IR radiation in pristine tissues, problems arise including the establishment of a close contact between the probe and the sample and contamination of the probe after contact. Therefore, the applications to tissues are less frequent than Raman fiber-optical applications.

\subsection{Raman spectroscopy}

For a long time, tissue fluorescence and the lack of appropriate, sensitive instrumentation were important obstacles in the biomedical application of Raman spectroscopy. When biological applications of Raman spectroscopy started more than 30 years ago, it took many hours to record spectra of highly purified and concentrated solutions of biomolecules. The problem of fluorescence, which overwhelms the Raman signal of most natural biological samples (including organic tissues) upon excitation in the visible region, has been largely overcome by the availability of instruments working in the NIR region of the spectrum. Fluorescence in Raman spectra from biomolecules can also be avoided by laser excitation in the deep UV because a fluorescence-free window exists with excitation below $270 \mathrm{~nm}$. However, deep UV excitation also harbors the risk of inducing photo-degradation damage.

The most commonly used Raman imaging instrument consists of a NIR solid state laser, a microscope with a motorized sample stage, a Notch filter for Rayleigh scattering suppression, a dispersive spectrometer and a charge coupled device (CCD) camera which is optimized for the NIR region [19]. Signal collection times could be reduced to the point where only seconds are required to obtain Raman spectra of cells and tissues. The time it takes to collect a Raman spectrum is of course crucial in Raman imaging applications as the spectra are usually collected sequentially in the mapping mode and the total acquisition time is the product of data points multiplied by the time per spectrum/point. Time is also an important issue in in vivo applications because of tissue movement caused by respiratory and vascular pulsations. 


\subsubsection{Raman imaging}

Three different Raman imaging methodologies have been developed namely (i) point and (ii) line mapping as representatives of serial imaging approaches, and (iii) direct or wide-field Raman imaging as representative of a parallel imaging approach. They have been compared with respect to acquisition times, image quality, spatial resolution, intensity profiles along spatial coordinates and spectral signal to noise ratios [20]. The wide-field approach employs global sample illumination. The inelastically scattered light from the sample is collected, projected and magnified onto a two-dimensional CCD detector. Most methods for wide-field Raman imaging use filters for wavelength selection such as dielectric, acousto-optic tunable and liquid-crystal tunable filters. In spite of its superior spatial resolution near $300 \mathrm{~nm}$, wide-field Raman imaging has not been applied for tissue studies so far.

Point and line Raman imaging involve either a laser spot or a laser line sample illumination. In point mapping, the laser spot is stepped or raster-scanned in two spatial dimensions with a spectrum being recorded at each position. For line mapping, the extension of point mapping, a laser line is generated by a cylindrical lens and raster-scanned along one dimension using a two-dimensional CCD detector. The spatial data are registered on the detector on a line parallel to the entrance slit of the spectrometer while the spectral information is dispersed perpendicularly. A second spatial dimension is recorded by scanning the sample perpendicular to the line focus. In spite of advantages in acquisition speed, line mapping has been less frequently used than point mapping for tissue studies so far.

\subsubsection{Raman fiber-optical probes}

For in vivo data acquisition, Raman systems are coupled to fiber-optical probes. A miniaturized probe was designed [21] and applied in various biomedical studies (e.g. [22-27]). These probes consist of one central excitation fiber, six surrounding collection fibers, internal "in-the-tip" filters and beveled fiber ends for optimized light collecting efficiency. Unfortunately, the production of these probes has stopped. Other filtered probes are commercially available to fill the gap (e.g. Inphotonics, USA; Kaiser Optical Systems, USA). However, probe dimensions are likely too large for many clinical applications, particularly endoscopic. Therefore, a miniaturized unfiltered fiber-optic probe was suggested as an alternative, because low-OH silica as core material shows only low spectral contributions in the high-wavenumber region from 2400 to $3800 \mathrm{~cm}^{-1}$ [28]. Other proprietary, non-commercial fiber-optical Raman probes use 15 fibers and a ball lens [29], six fibers [30] or one fiber [31-33] for signal collection. New developments include the PhAT probe (Kaiser Optical Systems, USA) with global illumination and an array of 50 collection fibers [34], hollow-core photonic crystal fiber-optic probes [35] and concentric rings of optical fibers used for spatially offset Raman spectroscopy [36].

\section{Biomedical applications}

The fields of applications for FTIR and Raman imaging / fiber-optic techniques and the frequency of publications are displayed in Fig. 3A. More than half of all papers were reported on one of the three fields bone, skin and brain tissue. Almost twice as much papers were published using IR spectroscopy (110, dark gray bars) than Raman spectroscopy (60, light gray bars). It is interesting to note that (i) most Raman studies were reported for skin, probably because it is the largest organ and it is easily accessible, (ii) only Raman studies were reported for ocular tissue and (iii) no Raman mapping or fiber optic studies were reported for cartilage, liver, heart and spleen.

Fig. 3B displays the number of publications in the considered fields since 1996. This starting year was selected because the first FTIR imaging spectrometer was presented in 1995 [37] and subsequently 
(A)

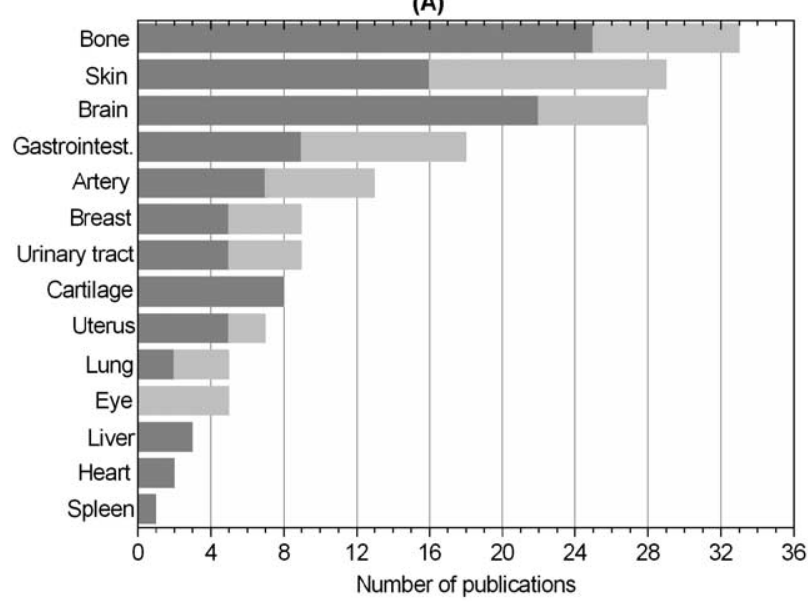

(B)

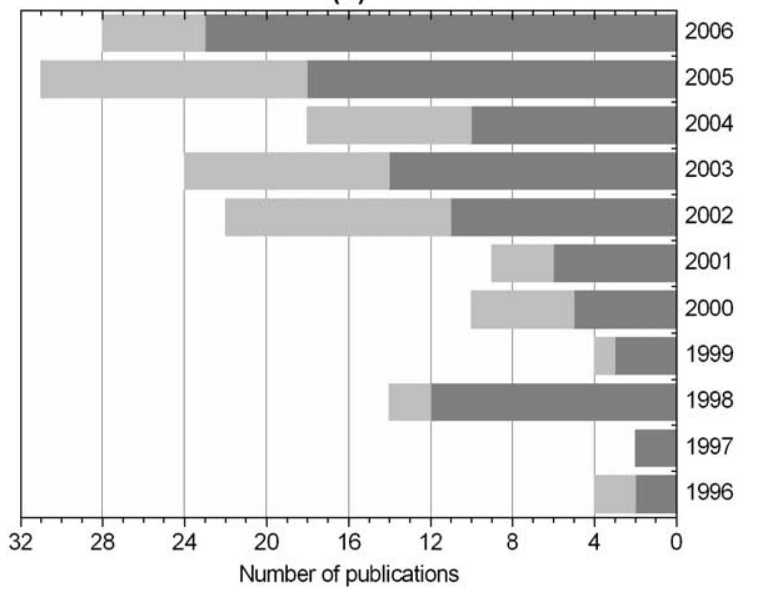

Fig. 3. (A) Diagram showing the fields of imaging and fiber-optic applications using FTIR (dark gray bars) or Raman techniques (light gray bars) and their frequency of publications. (B) Diagram displaying the number of publications per year in the fields shown in (A) using FTIR (dark gray bars) or Raman techniques (light gray bars) since 1996. For 2006 only papers until September were considered. Bars do not overlap.

applied. Moreover, sensitive NIR Raman spectrometers for mapping, imaging and fiber-optic coupling became available at the same time [19,38]. The numbers of IR studies are always higher than of Raman studies except for 2002 when a special issue on medical applications of Raman spectroscopy appeared in the "Journal of Raman Spectroscopy". Similarly, the relatively high numbers of IR studies in 1998 and in 2006, for which only papers until September were considered, are consequences of special issues which appeared in "Cellular and Molecular Biology" and "Biochimica et Biophysica Acta", respectively. A clear tendency is evident that the publication numbers increases from year to year. An even more pronounced increase is expected after the methods are introduced as standardized applications and transferred to clinics and laboratories.

\subsection{Mineralized tissue: bone, teeth}

\subsubsection{Bone}

IR and Raman spectroscopy have been used for several years to characterize mineralized structures in living organisms, notably bone and teeth [39]. With the application of imaging spectrometers to mineralized biological samples, spatial variations of the mineral content, mineral crystallinity, and the content/nature of the organic matrix consisting predominantly of collagen type 1 and cells are obtained. The spectral data can monitor the extent of mineral formation in tissue using a mineral to protein ratio. Other parameters monitor the size and perfection of the crystals and the ratio of carbonate ions and phosphate ions in the hydroxyapatite lattice. First IR images were reported from $5 \mu \mathrm{m}$ sections of canine alveolar bone tissue [40] and of human biopsies of the cortical region [41]. Studies on the chemical composition of bone were performed using synchrotron IR microspectroscopic mapping near the diffraction limit of 3-5 micrometer [42]. The three-dimensional chemical structure of bone was reconstructed from twodimensional FTIR images of 23 serial sections [9]. Different methods for processing mineralized tissue for FTIR spectroscopy and imaging in terms of fixation and embedding media were compared [43]. The structural properties of bone were examined by Raman imaging at $785 \mathrm{~nm}$ excitation with micrometer 
range spatial resolution $[44,45]$. Recently, Raman images from bone were also collected at $532 \mathrm{~nm}$ excitation after the fluorescence background was reduced by photochemical bleaching [46]. Advantages of the shorter excitation wavelength are higher quantum efficiency of CCD detectors and more intense Raman signals due the fourth power dependence of scattering intensity with excitation frequency. Both effects result in shorter acquisition times. Typically, Raman images of $300 \times 100 \mu \mathrm{m}^{2}$ areas with $2 \mu \mathrm{m}$ resolution just require 10 minutes. Raman spectra of bone could even be recorded non-invasively using a fiber-optic probe [36]. Studies of bone-related diseases include craniosynostosis by Raman imaging [47,48], osteoporosis [49,50], Fabry disease [51] and osteomalacia [52] by FTIR imaging. Additionally, FTIR imaging was used to study fracture healing of bone [53], bone fragility and collagen cross-links [54-57], effects of estrogen on bone quality in early postmenopausal women [58] and on fracture healing [59], skeletal mineralization in knockout mice [60-63] and the $\mathrm{CO}_{3}^{2-}$ content in bone mineral [64]. Microdamages in bone were investigated by FTIR imaging [65] and Raman imaging [66]. The large number of studies clearly demonstrates the efficacy of using FTIR and Raman imaging to detect and monitor pathological changes in bone.

\subsubsection{Teeth}

The potential environmental risk associated with mercury release has forced many European countries to ban the use of dental amalgam. Alternative materials such as composite resins do not provide the clinical function for the length of time characteristically associated with dental amalgam. The weak link in the composite restoration is the dentin/adhesive bond. The physicochemical interactions at the dentin/adhesive interface were characterized by FTIR imaging [67]. As compared to healthy dentin, differences were noted in depth of demineralization, adhesive infiltration and degree of conversion at the interface with caries-affected dentin. Dentin in teeth is also a useful model for the study of mineral maturation during biomineralization. Using FTIR imaging virtually all maturation stages in bovine dentin could be spectroscopically isolated and analyzed [68]. Another interesting application of Raman spectroscopy is the detection of dental caries in teeth. While optical coherence tomography was used to screen carious sites and to determine lesion depth, fiber-optical Raman spectroscopy provided biochemical confirmation of caries [69].

\subsection{Integumentary system: skin, hair}

As skin and hair belong to the so-called integumentary system of the body, both applications are discussed in one section. Human skin can be considered as a multilayered system. The structural organization of skin consists of units that have characteristic dimensions in the $10-500 \mu \mathrm{m}$ range. A detailed assessment of the components by FTIR imaging was reported using pig skin as an example [70]. The stratum corneum is the skin's outermost layer and the main protective barrier against water loss, microorganisms and toxic agents. The barrier function resides in the unusual lipid composition consisting of a roughly equimolar mixture of ceramides, free fatty acids and cholesterol, as well as some cholesterol esters and cholesterol sulfate. Due to the strong absorption of IR radiation by water, the penetration depth in naturally hydrated tissue such as skin is limited to a few micrometers. Therefore, in in vivo IR spectroscopy experiments which are performed in the ATR mode only the outermost layer of stratum corneum can be sampled [71]. The ATR technique was also coupled to IR fiber optics [15] and applied for FTIR imaging [13] to study the stratum corneum. It was recently summarized how FTIR imaging permits to monitor the effects of exogenous materials on stratum corneum lipid organization and protein structure [72]. In detail, FTIR imaging characterized the molecular composition of intact, thin skin sections [73], and imaged the distribution of exogenous molecules in skin [74]. Combined approaches of 
FTIR imaging with Raman imaging studied the permeation of lipids into skin $[75,76]$ and the structure during corneocyte maturation [77]. A widespread ex vivo method is tape-stripping whereby cell layers are removed from the stratum corneum with adhesive tape. Sequential tape stripping was employed in IR studies to obtain information about the depth distribution of molecular compounds in the stratum corneum [78]. Gram-Schmidt orthogonalization was applied to FTIR images of human skin biopsies to demonstrate its rapid reconstruction capability [79]. Confocal Raman microspectroscopy was applied to the stratum corneum to identify variations in keratin-containing areas [80] and to obtain depth profiles of molecular concentration gradients up to 200 micrometers [81]. The setup was applied as a non-invasive in vivo optical method to determine water concentration profiles of the stratum corneum and to determine changes therein as a result of hydration of the skin [82]. Its combination with the imaging modality confocal scanning laser microscopy provides optical sections of the skin without physically dissecting the tissue [83]. Using Raman imaging, heterogeneous domains in model stratum corneum lipid mixtures were observed [84]. Natural variations and reproducibility of Raman spectra of normal human skin was studied by a fiber-optic FT-Raman spectrometer [85]. However, exposure times of 8 min were reported with this technique, which is much longer than the exposure times for dispersive NIR Raman systems of $30 \mathrm{~s}$ for the low wavenumber region and $3 \mathrm{~s}$ for the high wavenumber region [81].

Since epithelial tissue covers the surface of hollow viscera and is exposed to a broad range of aggressive chemical and physical conditions, adenocarcinomas of glandular epithelium or carcinomas of squamous epithelium are among the most common forms of cancer (skin, breast, colon, prostate, cervix etc.). Skin cancer which includes squamous cell carcinoma, malignant melanoma and basal cell carcinoma, is the cancer with the highest incidence worldwide. Pigmented nevi which belong to benign skin lesions were distinguished from malignant skin lesions in thin sections of biopsies by FTIR imaging [86]. The melanotic zone of a malignant melanoma was earlier identified by FTIR mapping [87]. This distinction is important as the prognosis of melanoma is related to an early detection. Similarly, Raman spectroscopy was able to discriminate four different types of skin lesions in skin tumors [88]. Pseudocolor in vitro Raman maps were reconstructed to map precisely basal cell carcinoma [89]. Also the acquisition of in vivo Raman spectra from melanin in skin has recently been reported [90]. These papers indicate that FTIR and Raman spectroscopic-based methods may become valuable tools in dermatology and clinical methods for non-invasive in situ analysis and diagnosis of the skin.

The cross section of a human hair was imaged using synchrotron radiation [91] and conventional radiation [92]. The spatial resolution of ATR FTIR-imaging [92] was determined by measuring the distance over which the band absorbance changes from 95 to $5 \%$ of the maximum absorbance when passing through a sharp face. The spatial resolution of approximately 5 micrometer allowed imaging the medulla of the hair with an approximate diameter of 8 micrometer. The spatial resolution could even be enhanced by synchrotron radiation using a small aperture of $3 \times 3 \mu \mathrm{m}^{2}$ and a step size of $2 \mu \mathrm{m}$ [91].

\subsection{Brain}

Two main types of tissue are found in normal brain, referred to as white and gray matter, which consists of nerve fibers and glial cells, and of a combination of neurons and glial cells, respectively. Whereas white matter contains a higher lipid (15\%) and lower water $(70 \%)$ content, gray matter is characterized by a lower lipid (5\%) and higher water (83\%) content. Protein concentrations are similar (7.5-8.5\%) in white and gray matter. The first FTIR imaging study of monkey brain tissue employed an indium antimonide FPA detector with a restricted spectral range from 10000 to $1818 \mathrm{~cm}^{-1}$ [93]. Mercury cadmium telluride based FPAs also detect the fingerprint region below $1800 \mathrm{~cm}^{-1}$. Other early 
FTIR imaging papers visualized lipid and protein distributions in the cerebellum of rats with or without treatment by the antineoplastic drug cytarabine [94,95]. Furthermore, FTIR imaging was applied to investigate neuropathologic effects in mouse cerebella of a genetic lipid storage disease called NiemannPick type C [96]. In vitro Raman spectra of dura, gray matter and white matter of porcine brain tissue were obtained in the high wavenumber range using an unfiltered fiber-optic probe [28]. Signal collection times were only $1 \mathrm{~s}$.

FTIR mapping studies characterized multiple sclerosis lesions [97] and amyloid plaques in Alzheimerdiseased brain tissue sections [98]. Amyloids consist of aggregated proteins and peptides. Synchrotronbased FTIR imaging also showed focalized accumulation of $\mathrm{Cu}$ and $\mathrm{Zn}$ co-localized with amyloid deposits [99]. Transmissible spongiform encephalopathies, such as bovine spongiform encephalopathy in cattle and Creutzfeld-Jakob disease in human, are another group of protein-related neurodegenerative disorders. Transmissible spongiform encephalopathies-associated changes were detected in a hamster brain model by FTIR mapping [100-103] and FTIR imaging [104]. The IR spectra revealed regions of decreased $\alpha$-helical content and elevated $\beta$-sheet structure in and around infected neurons.

Brain tumors are classified according to their primary cells and to their malignancy. The most frequent brain tumors, called gliomas, originate from glial cells. The second abundant brain tumors, called meningeomas, originate from the meninges that envelop the central nervous system. Brain metastases are secondary tumors which originate from primary tumors outside the brain with the most frequent sites lung, colon, breast, kidney and skin. Raman maps of 20 tissue sections discriminated necrotic tissue from gliomas [105]. In another study, Raman maps of 20 tissue sections distinguished meningeoma from normal dura mater that is one layer of the meninges [106]. FTIR maps of 71 specimens revealed a correlation between the increase of malignancy of gliomas and decrease of the lipid to protein ratio [107]. The results were transferred to Raman maps from pristine brain tissue [108]. Classification models were developed to determine the tumor grade of gliomas from FTIR maps [109] and FTIR images [110-112]. Other classification models were trained to identify the primary tumors from brain metastasis by the spectroscopic fingerprints which were obtained from FTIR images [113,114]. Further studies described FTIR and Raman images from meningeomas [115], brain tissue characterization using high wavenumber Raman spectroscopy [116] and FTIR images from glioma models of rats [117,118]. In a forthcoming paper, tumor cells of malignant melanomas were identified in Raman maps which were recorded from whole mouse brains by a fiber-optic coupled Raman system with a motorized stage. Here, the detection of tumor cells within white and gray matter of normal brain tissue was facilitated by resonance-enhanced spectral contributions of melanin (Fig. 4A). Beside an extended tumor, another smaller tumor of approximately $240 \times 240 \mu \mathrm{m}^{2}$ was identified in the Raman map (Fig. 4B). These studies demonstrate that Raman-based methods might enable intra-operative distinction between normal brain tissue and tumors. This is particular important in neurosurgery in order to maximally resect tumor cells upon minimum disturbance of normal brain functions.

\subsection{Gastrointestinal tract: oral tissue, intestinal tissue, esophagus}

\subsubsection{Oral tissue}

The detection of dysplasia and early cancer is important because of the improved survival rates associated with an early treatment. Dysplasia in the palate of rats was induced by topical application of a carcinogen. Normal, low and high grade dysplastic tissues were classified by Raman spectra which were collected in vivo by a fiber-optic probe coupled to a Raman spectrometer with a NIR excitation laser [23]. Raman spectra with $100 \mathrm{~s}$ integration time were recorded to create classification models. 


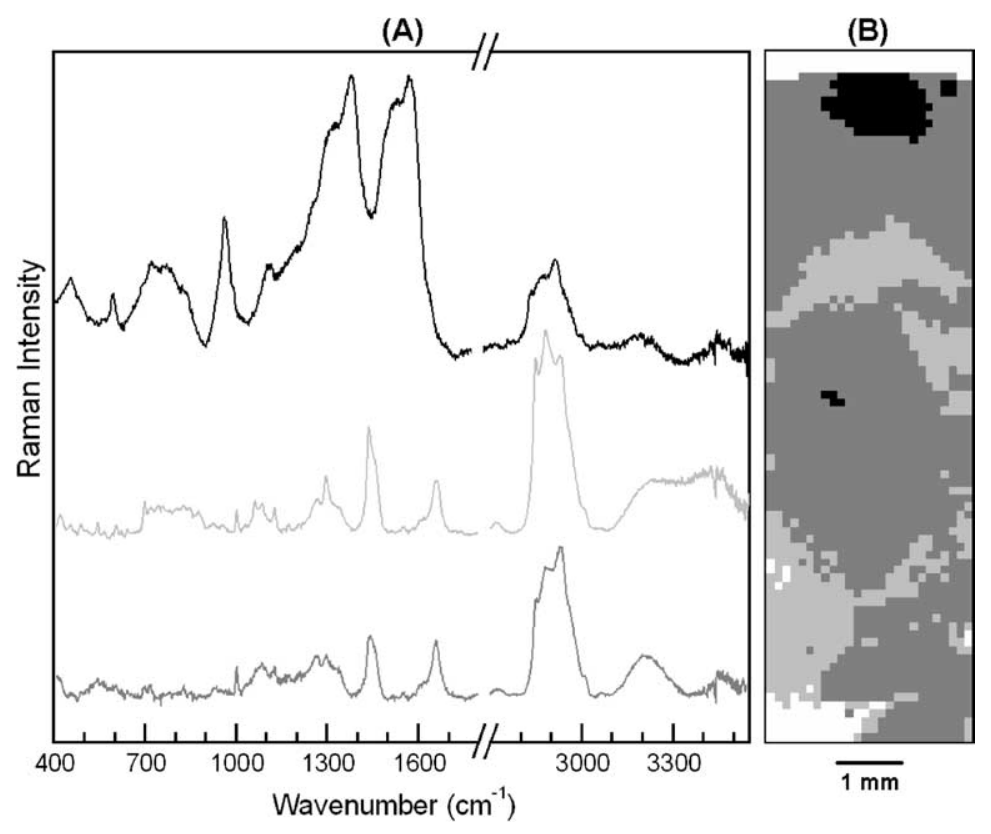

Fig. 4. Raman spectra from 400-1800 and 2700-3550 $\mathrm{cm}^{-1}$ (A) and Raman map (B) of murine brain tissue. The color code represents the result of a cluster analysis: white matter (light gray), gray matter (dark gray), brain metastases of malignant melanoma (black).

These were tested with an independent set of spectra obtained using signal collection times of $10 \mathrm{~s}$. Malignant from normal human oral tissue in more than 30 fresh samples was also distinguished using FTIR fiber-optic techniques [16].

Squamous cell carcinoma (SCC) is a malignant tumor of epithelium that may occur in cheek mucosa, tongue, soft palate, gingival and the floor of the mouth. SCCs were analyzed by FTIR mapping and the findings were compared to histopathology [119]. A murine model of SCC was studied by FTIR imaging [120]. Molecular changes in necrotic tissue were observed which were correlated with accumulation of cholesterol and with protein secondary structures. DNA and keratin containing tissue structures which were visualized by FTIR mapping revealed distinct differences between normal tissue and SCC [121]. Cancer cells were found to produce relatively homogenous and clearly abnormal cell biochemistry, whereas differentiated epithelial cells present a very heterogeneous distribution of cellular components. The abnormal keratin distribution in poorly differentiated SCC and in keratin pearls, which are present only in well-differentiated SCC, offers insight into the process of malignant tissue transformation in squamous epithelium. IR spectra from selected pearls reveal that in the center of keratin pearls the concentration of cytokeratin proteins is abnormally high, that DNA is absent and that the cell fluidity is reduced [122]. Using these features, tissue containing abnormal or cancer cells could be distinguished from normal epithelial structures.

As fibrosarcoma - a malignant tumor derived from fibrous connective tissue - occurs most frequently in the mouth of dogs, Raman spectroscopy of fibrosarcoma was included to this section [123]. Fibrosarcoma cells were subcutaneously implanted in mice, in vivo Raman spectra with an autofluorescence background were acquired in $5 \mathrm{~s}$ using a fiber-optic probe and multivariate algorithms were developed to discriminate tumors from normal tissue. This group also studied normal and cancerous tissue of the nasopharynx by the same technique [124]. 


\subsubsection{Intestinal tissue}

Colorectal adenocarcinomas originate from epithelial cells and are able to infiltrate the subjacent layers of colon and rectum. The morphology of these carcinomas in thin tissue sections was studied by FTIR mapping $[87,125,126]$. These data sets were used to demonstrate data analyses by functional group mapping, principal component analysis, artificial neural networks and different clustering techniques such as k-means, fuzzy C-means and agglomerative hierarchical clustering. Up to eleven clusters could be assigned to several histological features. Human colon carcinoma under humid condition was used as target to detect malignant tissue by fiber-optical IR spectroscopy [17].

The feasibility of fiber-optic coupled Raman spectroscopy for disease classification was demonstrated during in vivo clinical gastrointestinal endoscopy [22]. The fiber-optic probe was passed through the endoscope instrument channel, placed in contact with the tissue surface and spectra could be obtained in $5 \mathrm{~s}$. The same group also differentiated adenomatous from hyperplastic polyps in the colon using the same fiber-optic Raman system [26].

\subsubsection{Esophagus}

Long periods of exposure to gastroesophageal reflux can lead to a change in the lining of esophagus, whereby the normal squamous epithelial lining is replaced by protective columnar epithelial cells. This is termed Barrett's esophagus and is associated with an increased risk of developing esophageal adenocarcinoma. Patients with Barrett's esophagus undergo periodic endoscopic surveillance with multiple biopsy examinations in an attempt to differentiate inflammation from dysplastic and early cancerous lesions at a time when intervention can be beneficial. However, this surveillance approach is hindered by low sampling yield, random sampling error, pathology-associated costs and delay in diagnosis. Fiber-optic Raman spectroscopy was recognized to enhance lesion detection in premalignant conditions. A Raman study of 89 esophageal samples from 44 patients was reported [127,128]. Other normal and abnormal epithelial tissues from the larynx, tonsil, stomach, bladder and prostate were included in this investigation. Comparison of prediction of Raman spectral classification models with pathology gave sensitivities of 73-100\% and specificities of 90-100\%. Raman spectra of the rat esophagus were collected ex vivo with three different fiber-optic probes in order to mimic instrument calibration, probeto-probe and day-to-day variations [25]. Barrett's and normal epithelium could be discriminated with accuracy higher than $93 \%$. Another ex vivo study used Raman imaging to analyze tissue sections from 29 esophageal biopsies [129]. Pathologists reviewed contiguous histopathologically stained tissue sections. Objective was to study the biochemical changes that distinguish the different stages of the disease Barrett's esophagus.

\subsection{Blood vessels}

Previous research has suggested that rather the microscopic morphology and chemical composition than the anatomy of an atherosclerotic plaque in blood vessels determine plaque stability and disease progression. For this reason, FTIR mapping [130,131], FTIR imaging [13,132-134] were applied to obtain both chemical and spatial information on the distribution of different components within atherosclerotic arteries. Whereas the first study examined atherosclerotic human artery under moist conditions and the second study the calcification of thin dried sections of rabbit aortas both in transmission mode, the last three studies applied a micro-ATR approach in reflection mode for detailed imaging of atherosclerotic arteries. Beside atherosclerosis, aneurism is another common cardio-vascular pathology which has recently been studied by FTIR imaging [135]. 
Raman spectroscopy was extensively used to study atherosclerosis. Developments of compact clinical Raman systems, specially developed Raman catheters and future directions of Raman spectroscopy in cardiovascular medicine were summarized [136]. The performance of a new fiber-optic probe was tested in vitro with aorta tissue [29]. Raman maps of human atherosclerotic plaques were generated to investigate the chemical composition of the pigment ceroid in cross sections of the intimal surface [137] and to investigate plaque development in mice [138]. Compact clinical Raman systems and dedicated, miniaturized fiber-optic Raman catheters were used ex vivo in human coronary arteries [139] and in vivo in lambs and sheeps to illuminate the blood vessel wall and to collect Raman scattered light [24]. The in vivo intravascular Raman signal obtained from a blood vessel was found to be a simple summation of signal contributions of the blood vessel wall and of blood. Algorithms previously developed from single point Raman spectra could be adapted to extract information about the chemical composition of blood vessel walls from Raman spectra.

\subsection{Breast}

Between 1 and 2 million woman in the U.S. have silicon breast implants. In order to accurately assess the role of silicone and other foreign materials in any histological change, it is necessary to detect them. The presence, size and chemical compositions of silicon gel inclusions in human breast tissue were determined by Raman imaging [38], FTIR imaging [140] and FTIR mapping [141].

After skin cancer, breast cancer is the second most frequently diagnosed cancer in woman. Each adult female breast is divided into compartments called lobes which are further subdivided into smaller compartments called lobules which end in acini. All compartments are linked by thin tubes called ducts. There are 12 different types of breast cancer with the most common being ductal carcinomas, which begin in the lining of the ducts, and lobular carcinoma, which begin in the lobules. FTIR imaging was applied to malignant and benign breast tumor tissue sections [142-144]. The latter study classified benign lesions fibroadenoma from 14 patients, malignant ductal carcinoma in situ from 8 patients, connective tissue and adipose tissue by artificial neural network analysis. These papers revealed that breast tissue microheterogeneity is a particularly severe problem for FTIR microspectroscopy and that high-quality spectra with high spatial resolution are required in order to detect subtle, cancer related alterations in the biochemical and morphological composition of tissue at the microscopic level. These data also suggested that earlier reported spectral changes between malignant and normal tissues which were observed in single spectra at higher spatial resolution may have an alternative explanation. Raman mapping assessed the chemical composition and morphology of breast tissue [145] and lymph nodes in tissue sections of breast cancer patients [146]. Shafer-Peltier presented a model in [145], which fits macroscopic tissue spectra with a linear combination of basis spectra derived from spectra of the cell cytoplasm, cell nucleus, fat, beta carotene, collagen, calcium hydroxyapatite, calcium oxalate dihydrate, cholesterol-like lipid deposits and water. Raman fiber-optical probes are under development to classify normal breast tissue, benign disease and malignant breast cancer in vivo during breast lumpectomy surgeries [147]. The instrument is capable of collecting and processing Raman spectra in less than $2 \mathrm{~s}$.

\subsection{Urinary tract: prostate, bladder}

Prostate tissue is structurally complex, consisting primarily of glandular ducts lined by epithelial cells and supported by heterogeneous stroma, and containing also blood vessels, blood, nerves, ganglion cells, lymphocytes and stones. Benign prostatic hyperplasia is one of the most common diseases in elderly 
men. It describes an overgrowth of the epithelial and fibromuscular tissues in the human prostate, in which both epithelium and stroma continue to proliferate at different rates. Reflectance FTIR imaging was used to examine the structural changes of compartments in tissue sections [148].

Histopathological typing using the Gleason grading system is the standard approach for grading prostate cancer and provides an indication as to the aggressiveness of the tumor. However, this system is based upon a visual criterion of pattern recognition that is operator-dependent and subject to intra- and inter-observer variability. Thus, there is a need for molecular based techniques to grade tissue samples in a reliable and reproducible manner. FTIR imaging of microarrays was coupled with statistical pattern recognition techniques in order to demonstrate histopathologic characterization of prostatic tissue and to differentiate benign from malignant prostatic epithelium $[3,149,150]$. The microarray contained 86 samples with up to eight samples from 16 patients. Altogether, the authors recorded more than 9.5 million spectra from over 870 samples and reported a subset of ca. 3 million spectra from 262 samples. The high throughput sampling and detection methodology afforded by tissue microarrays, spectroscopic imaging and fast classification algorithms, enabled the measurement of high and low abundant cell types. However, the presented, nearly perfect recognition accuracies are unrealistic high and should be considered with caution [151]. A prototype diagnostic classifier for Gleason graded prostate cancer based upon FTIR spectroscopy and linear discriminant analysis demonstrated 80\% agreement with histology [152].

29 bladder samples and 38 prostate samples were studied in vitro by a Raman system coupled to a fiber-optic probe [27]. The spectra were correlated with the histologic features and used to develop classifications models. The bladder algorithm was able to differentiate benign samples (e.g. normal and cystitis) from malignant samples (e.g. transitional cell carcinoma). The prostate algorithm was able to differentiate benign samples (e.g. prostatic hyperplasia and prostatitis) from malignant samples (prostate cancer). Testicular microlithiasis is associated with various benign and malignant conditions. Microliths in six samples were investigated by Raman imaging in order to identify their molecular constitution [153]. The results showed that microliths are composed of pure hydroxyapatite and that glycogen deposits surround all microliths in the samples associated with germ cell neoplasms but not in the benign case. Kerr-gated Raman spectroscopy uses a picosecond pulsed laser as well as fast temporal gating of collected Raman scattered light. This technique suppresses signals from both surface and deep layers in bladder and prostate tissue and enables collecting of Raman spectra from different depths [154]. Another new approach used high wavenumber Raman spectroscopy to image bladder tissue sections [116].

\subsection{Cartilage}

Articular cartilage is a type of dense connective tissue that provides resistance to compressive forces during joint movements. It consists of chondrocytes cells embedded in an extracellular matrix composed predominantly of a hydrophilic proteoglycan gel enmeshed in a dense network of type II collagen fibrils. The proteoglycans are composed of core proteins to which are attached numerous glycosaminoglycans such as keratan sulfate and chondroitin sulfate. The composition of the extracellular matrix of cartilage dictates its mechanical properties. As FTIR imaging is an analytical technique that accurately quantifies spatial and temporal changes in matrix composition, it may be extremely valuable in characterizing the progression of degenerative cartilage diseases as well as the efficacy of potential therapies. The primary components collagen, proteoglycan, non-collagenous proteins and chondrocytes cells in histological sections of cartilage were determined by FTIR imaging [155,156]. FTIR imaging also studied genetically modified bovine chondrocytes, how the newly formed matrix is integrated into the articular cartilage substrate and how the collagen and proteoglycan components are distributed in the repair tissue [157]. 
Proteoglycan content and distribution in tissue engineered cartilage were determined using FTIR imaging [158]. This cartilage was grown from chondrocytes within a hollow fiber bioreactor. A recent study elucidated several IR spectroscopic parameters that enable evaluation of molecular and compositional changes in human cartilage with arthritis, a progressively disabling disease of the joints, and in repair cartilage from animal models [159]. Collagen fibril orientation was determined using polarized FTIR imaging [160] and degenerative cartilage was also analyzed using an IR fiber-optic probe $[18,161]$.

\subsection{Tissue and cells of cervix uteri}

One field of research that received considerable attention in the previous decade was the application of IR and Raman spectroscopy to gynecological screening for cervical dysplasia and malignancies. The initial work of Wong and coworkers on FTIR spectroscopy of cervical cancer started the field of "FTIR diagnostics" [162]. Since then most FTIR studies have been performed on exfoliated cervical cells and their main objective has been to improve the diagnostic accuracy of the Papanicolaou smear [163]. FTIR mapping [164,165] and FTIR imaging [10,166,167] examined cervical tissue sections. A villoglandular adenocarcinoma from a cervical biopsy was used as a model system to demonstrate a three-dimensional image processing technique for FTIR images [10]. Steller and coworkers faced two general problems [167]. First, FTIR microspectroscopic imaging of extended specimens generates large data sets which requires optimized procedures for data analysis. Second, whereas the spectral signatures of the cervical stroma, inflammatory infiltration, blood vessels and the intermediate and superficial cell layers of normal squamous epithelium show clear differences, the IR spectra of basal cell layer of normal epithelium and of SCC are highly similar. In spite of these similarities, normal, premalignant and malignant tissues were distinguished in FTIR images with high accuracy by a combined analysis of fuzzy and hierarchical clustering. Focus of the Raman spectroscopic research on cervical tissue is not classification of tissue in thin sections, but in vivo assessment of squamous dysplasia by fiber-optic probes [31,32]. Whereas the first study reported the design and testing of a fiber-optical Raman system, the second study presented the results of a pilot clinical trial at three clinical sites. Raman spectra were measured from one colposcopically normal and one abnormal area of the cervix in 13 patients. Comparison to histologic analysis revealed that the spectral data were able to identify high-grade squamous dysplasia, misclassifying only one sample.

\subsection{Lung}

Lung cancer is the second most common cancer in humans and the most common cause of cancer deaths in the world. A Raman study of bronchial tissue investigated 28 specimens [168] using a Raman spectrometer with $785 \mathrm{~nm}$ excitation coupled to a fiber-optic probe which was developed earlier for skin studies [33]. Raman spectra were collected with $5 \mathrm{~s}$ exposure time and the spectral differences between normal and neoplastic tissues were analyzed. Another experimental approach using $1064 \mathrm{~nm}$ excitation, a fiber-optic probe and a newly developed multi-channel detector was presented to measure Raman spectra of seven lung tissue specimens [169]. The data obtained with 400 s exposure time distinguished normal and cancerous tissue and also two different types of lung carcinomas. Characterization of the biochemical composition of normal bronchial tissue is important to understand the biochemical changes that accompany lung cancer development. Frozen sections of normal bronchial tissue were studied by Raman imaging [170]. Subsequent comparison of Raman images with histologic evaluation of stained sections enabled to identify the spectral features of bronchial mucus, epithelium, fibrocollagenous stroma, smooth muscle, glandular tissue and cartilage. Sections containing both cancerous and 
noncancerous lung tissue were also studied by FTIR mapping [171]. Lung cancer is usual fatal once it becomes metastatic. In order to develop metastases, neoplastic cells invade the basal membrane and enter the vascular or lymphatic system. A three-dimensional artificial membrane model was established in order to investigate invasion of lung cancer cells by FTIR imaging [172].

\subsection{Ocular tissue}

Age-related macular degeneration is a major cause for visual loss. Carotenoid pigments may provide protection against light-induced oxidative damage and lower the risk for this pathology. Carotenoid levels in the retina of living human eyes were determined non-invasively by Raman spectroscopy [173]. The method takes advantage that contributions of carotenoids in Raman spectra are resonant enhanced and that no other biological molecules found in significant concentrations in human ocular tissues exhibit similar resonant enhancement with laser excitation at $488 \mathrm{~nm}$ so the in vivo carotenoid Raman spectra are remarkably free of confounding responses. Raman instruments were designed for this special application. The next generation of ocular resonance Raman scanners will incorporate wide-field imaging of macular carotenoid distributions [174]. Raman spectroscopy was also applied to image the vitreous in order to detect altered vitreous molecules such as glycated collagen in diabetic vitreopathy [175]. The detection of glutamate in the vitreous of porcine eyes was reported in another Raman study [176]. Glutamate, a by-product of nerve cell death, is an indicator of glaucoma and diabetic retinopathy. Using filipin as an external Raman label, which binds specifically to cholesterol, the distribution of cholesterol in a rat eye lens was determined by Raman spectroscopy [177].

\subsection{Liver}

Liver fibrosis is an adaptive response to chronic metabolic, toxic, microbial, viral, circulatory or neoplastic hepatic injuries and may eventually progress to cirrhosis. The result is a destruction of the normal hepatic architecture that is replaced by regenerating hepatocyte nodules that are encompassed by fibrous septa. It is generally considered that liver fibrosis is reversible while cirrhosis is irreversible. Although there are several non-invasive methods available to monitor the progression of liver fibrogenesis, they cannot reliably detect fibrosis in its early stages, when the progress can be stopped or reversed by removing or eliminating the underlying, etiological agent that causes the hepatic injury. Early fibrosis alterations in liver sections from a rat model were characterized by biochemistry, immunofluorescence microscopy and synchrotron FTIR mapping [178]. Of particular interest was the collagen distribution in FTIR images which correlated well with corresponding images provided by immunofluorescence imaging. Sections of cirrhotic liver tissue were selected to demonstrate the power of FTIR mapping [179]. The spectral properties on the microscopic level agreed extremely well with the known histopathology. FTIR mapping was also applied to characterize the differences between normal and hypercholesterolemic rabbit liver [180]. The authors reported that cholesterol esters, most likely in the form of lipoprotein complexes, accumulate in the hypercholesterolemic liver.

\subsection{Heart}

Fibrillar collagens are major proteins of the cardiac extracellular matrix and play a significant role in the structural organization of the healthy heart. Abnormal rearrangement of remodeling of the cardiac extracellular matrix is known to contribute to cardiac dysfunction. Microscopic multifocal necrosis and scarring were induced in a hamster model. The patterns of cardiac collagen deposition between control, 
untreated and treated cardiomyopathic hearts were studied by FTIR mapping using synchrotron [181] and conventional globar IR radiation [182].

\subsection{Spleen}

Germinal centers are important components of the adaptive immune response that take place in secondary lymphoid organs such as the spleen and tonsils. Standard procedures in immunology for identification of $\mathrm{B}$ and $\mathrm{T}$ cells in spleen are methods that detect variations in morphology, tissue architecture, staining patterns or sensitivity to a number of specific antibodies. FTIR mapping and imaging were applied to tissue sections of spleen to distinguish anatomical features such as primary and secondary follicles, T zones, arteries and spleen red pulp [183]. The results were compared with consecutive sections stained by immunohistochemical procedures and with $\mathrm{T}$ and $\mathrm{B}$ lymphocytes which were extracted from human blood. It was concluded that sensitivity and specificity of IR-based methods are comparable to those of standard methods for identification of B and T cells. However, FTIR imaging offers advantages in velocity, data throughput and standardization because of minimal sample preparation.

\section{Conclusions}

This contribution reviewed the enormous progress of vibrational spectroscopic imaging over the past decade. The methods were applied to recognize tissue types and characterize diseases. The ability to utilize just one tissue section to obtain biochemical information is a major advantage. In contrast, the use of standard histological techniques generally requires preparing individual tissue sections for staining each component of interest. The approaches demonstrated that pathologic changes can now be defined by biochemistry-based, objective spectroscopic criteria that do not require a pathologist's interpretation.

The challenges of in vivo fiber-optic Raman spectroscopy are relative weak signals from tissue, interference from tissue fluorescence and spectral contamination caused by the background signal generated in the fiber-optic materials. Fiber-optic Raman probes have been shown to collect single spectra, but fiber-optic, wide-field Raman imaging still need to be developed. Multimodal approaches might be an alternative way, that means a combination of multiple optical spectroscopic or imaging techniques. For instance, suspicious areas could be detected by wide-field fluorescence imaging and its dysplastic nature characterized and graded by single-point Raman spectroscopy. Future improvements in instrumentation and data analysis will further extend the biomedical applicability and finally result in implementation of these innovative techniques into the clinic.

\section{Acknowledgements}

The authors thank Daniela Codrich (Children Hospital Burlo Garofolo, Trieste) for careful reading of the manuscript. This work has been partly funded through the MIUR/CENMAT initiative, and partly through the INFRAEUR/BINASP project.

\section{References}

[1] E.B. Hanlon, R. Manoharan, T.W. Koo, K.E. Shafer, J.T. Motz, M. Fitzmaurice, J.R. Kramer, I. Itzkan, R.R. Dasari and M.S. Feld, Prospects for in vivo Raman spectroscopy, Phys. Med. Biol. 45 (2000), R1-R59. 
[2] R.K. Dukor, Vibrational spectroscopy in the detection of cancer, in: J.M. Chalmers and P.R. Griffiths (Eds), Handbook of Vibrational Spectroscopy, John Wiley \& Sons Ltd, Chichester, 2002, 3335-3361.

[3] I.W. Levin and R. Bhargava, Fourier transform infrared vibrational spectroscopic imaging: integrating microscopy and molecular recognition, Annu. Rev. Phys. Chem. 56 (2005), 429-474.

[4] M. Diem, M. Romeo, S. Boydston-White, M. Milkovic and C. Matthäus, A decade of vibrational micro-spectroscopy of human cells and tissue, Analyst. 129 (2005), 880-885.

[5] D.I. Ellis and R. Goodacre, Metabolic fingerprinting in disease diagnosis: biomedical applications of infrared and Raman spectroscopy, Analyst. 131 (2006), 875-885.

[6] N. Jamin, P. Dumas, J. Moncuit, W.H. Fridman, J.L. Teillaud, G. Lawrence and G.P. Williams, Highly resolved chemical imaging of living cells by using synchrotron infrared microspectrometry, Proc. Natl. Acad. Sci. USA 95 (1998), 48374840.

[7] P. Lasch, M. Boese, A. Pacifico and M. Diem, FTIR spectroscopic investigations of single cells on the subcellular level, Vib. Spectrosc. 28 (2002), 147-157.

[8] C. Krafft, T. Knetschke, R.H.W. Funk and R. Salzer, Studies on stress-induced changes at the subcellular level by Raman microspectroscopic mapping, Anal. Chem. 78 (2006), 4424-4429.

[9] H. Ouyang, E.P. Paschalis, A.L. Boskey and R. Mendelsohn, Chemical structure-based 3D reconstruction of human cortical bone from 2D-IR images, Appl. Spectrosc. 56 (2002), 419-422.

[10] B.R. Wood, K.R. Bambery, C.J. Evans, M. Quinn and D. McNaughton, A three-dimensional multivariate image processing technique for the analysis of FTIR spectroscopic images of multiple tissue section, BMC Med. Imaging 6 (2006), 12.

[11] L.M. Miller and P. Dumas, Chemical imaging of biological tissue with synchrotron infrared light, Biochim. Biophys. Acta 1758 (2006), 846-857.

[12] P. Lasch and D. Naumann, Spatial resolution in infrared microspectroscopic imaging of tissues, Biochim. Biophys. Acta 1758 (2006), 814-829.

[13] S.G. Kazarian and K.L.A. Chan, Application of ATR-FTIR spectroscopic imaging to biomedical samples, Biochim. Biophys. Acta 1758 (2006), 858-867.

[14] H.M. Heise, L. Küpper and L.N. Butvina, Bio-analytical applications of mid-infrared spectroscopy using silver halide fiber-optic probes, Spectrochim. Acta B 57 (2002), 1649-1663.

[15] L. Brancaleon, M.P. Bamberg and N. Kollias, Spectral differences between stratum corneum and sebaceous molecular components in the mid-IR, Appl. Spectrosc. 54 (2000), 1175-1182

[16] J.G. Wu, Y.Z. Xu, C.W. Sun, R.D. Soloway, D.F. Xu, Q.G. Wu, K.H. Sun, S.F. Weng and G.X. Xu, Distinguishing malignant from normal oral tissue using FTIR fiber-optic techniques, Biopolymers 62 (2001), 185-192.

[17] U. Bindig, H. Winter, W. Wäsche, K. Zelianeos and G. Müller, Fiber optical and microscopic detection of malignant tissue by use of infrared spectrometry, J. Biomed. Optics 7 (2002), 100-108.

[18] P.A. West, M.P.G. Bostrom, P.A. Torzilli and N.P. Camacho, Fourier transform infrared spectral analysis of degenerative cartilage: an infrared fiber-optic probe and imaging study, Appl. Spectrosc. 58 (2004), 376-381.

[19] M.G. Shim and B.C. Wilson, Development of an in vivo Raman spectroscopic system for diagnostic applications, $J$. Raman Spectrosc. 28 (1997), 131-142.

[20] S. Schlücker, M.D. Schaeberle, S.W. Huffmann and I.W. Levin, Raman microspectroscopy: a comparison of point, line, and wide-field imaging methodologies, Anal. Chem. 75 (2003), 4312-4318.

[21] M.G. Shim, B.C. Wilson, E. Marple and M. Wach, Study of fiber-optic probes for in vivo medical Raman spectroscopy, Appl. Spectrosc. 53 (1999), 619-627.

[22] M.G. Shim, L.M. Wong Kee Song, N.E. Marcon and B.C. Wilson, In vivo near-infrared Raman spectroscopy: demonstration of feasibility during clinical gastrointestinal endoscopy, Photochem. Photobiol. 72 (2000), 146-150.

[23] T.C. Bakker Schut, M.J.H. Witjes, H.J.C.M. Sterenborg, O.C. Speelman, J.L.N. Roodenburg, E.T. Marple, H.A. Bruining and G.J. Puppels, In vivo detection of dysplastic tissue by Raman spectroscopy, Anal. Chem. 72 (2000), 6010-6018.

[24] H.P. Buschmann, E.T. Marple, M.L. Wach, B. Bennet, T.C. Bakker Schut, H.A. Bruining, A.V. Bruschke, A. van der Laarse and G.J. Puppels, In vivo determination of the molecular composition of artery wall by intravascular Raman spectroscopy, Anal. Chem. 72 (2000), 3771-3775.

[25] I.A. Boere, T.C. Bakker Schut, J. van den Boogert, R.W.F. de Bruin and G.J. Puppels, Use of fiber-optic probes for detection of Barrett's epithelium in the rat oesophagus by Raman spectroscopy, Vib. Spectrosc. 32 (2003), 47-55.

[26] A. Molckovsky, L.M. Wong Kee Song, M.G. Shim, N.E. Marcon and B.C. Wilson, Diagnostic potential of nearinfrared Raman spectroscopy in the colon: differentiating adenomatous from hyperplastic polyps, Gastrointest. Endosc. 57 (2003), 396-402.

[27] P. Crow, A. Molckovsky, N. Stone, J. Uff, B. Wilson and L.M. Wong Kee Song, Assessment of fiber-optic near infrared Raman spectroscopy for diagnosis of bladder and prostate cancer, Urology 65 (2005) 1126-1130.

[28] L.F. Santos, R. Wolthuis, S. Koljenovic, R.M. Ameida and G.J. Puppels, Fiber-optic probes for in vivo Raman spectroscopy in the high-wavenumber region, Anal. Chem. 77 (2005), 6747-6752. 
[29] J.T. Motz, M. Hunter, L.H. Galindo, J.A. Gardecki, J.R. Kramer, R.R. Dasari and M.S. Feld, Optical fiber-probe for biomedical Raman spectroscopy, Appl. Optics 43 (2004), 542-554.

[30] C.J. Barbosa, F.H. Vaillancourt, L.D. Eltis, M.W. Blades and R.F.B. Turner, The power distribution advantage of fiberoptic coupled ultraviolet resonance Raman spectroscopy for bioanalytical and biomedical applications, J. Raman Spectrosc. 33 (2002), 503-510.

[31] A. Mahadevan-Jansen, M.F. Mitchell, N. Ramanujam, U. Utzinger and R. Richards-Kortum, Development of a fiber-optic probe to measure NIR Raman spectra of cervical tissue in vivo, Photochem. Photobiol. 68 (1998), 427-431.

[32] U. Utzinger, D.L. Heintzelman, A. Mahadevan-Jansen, A. Malpica, M. Follen and R. Richards-Kortum, Near-infrared Raman spectroscopy for in vivo detection of cervical precancers, Appl. Spectrosc. 55 (2001) 955-959.

[33] Z. Huang, H. Zeng, I. Hamzavi, D. McLean and H. Lui, Rapid near-infrared Raman spectroscopy system for real-time in vivo skin measurements, Opt. Lett. 26 (2001), 1782-1784.

[34] M.V. Schulmerich, W.F. Finney, R.A. Fredricks and M.D. Morris, Subsurface Raman spectroscopy and mapping using a globally illuminated non-confocal fiber-optic array probe in the presence of Raman photon migration, Appl. Spectrosc. 60 (2006), 109-114.

[35] S.O. Konorov, C.J. Addison, H.G. Schulze, R.F. Turner and M.W. Blades, Hollow-core photonic crystal fiber-optic probes for Raman spectroscopy, Opt. Lett. 31 (2006), 1911-1913.

[36] P. Matousek, E.R. Draper, A.E. Goodship, I.P. Clark, K.L. Ronayne and A.W. Parker, Noninvasive Raman spectroscopy of human tissue in vivo, Appl. Spectrosc. 60 (2006), 758-763.

[37] E.N. Lewis, P.J. Treado, R.C. Reeder, G.M. Story, A.E. Dowrey, C. Marcott and I.W. Levin, Fourier transform spectroscopic imaging using an infrared focal plane array detector, Anal. Chem. 67 (1995), 3377-3381.

[38] M.D. Schaeberle, V.F. Kalasinsky, J.L. Luke, E.N. Lewis, I.W. Levin and P.J. Treado, Raman chemical imaging: histopathology of inclusions in human breast tissue, Anal. Chem. 68 (1996), 1829-1833.

[39] A.L. Boskey and R. Mendelsohn, Infrared spectroscopic characterization of mineralized tissues, Vib. Spectrosc. 38 (2005), 107-114.

[40] C. Marcott, R.C. Reeder, E.P. Paschalis, D.N. Tatakis, A.L. Boskey and R. Mendelsohn, Infrared microspectroscopic imaging of biomineralized tissues using a mercury-cadmium-telluride focal plane array detector, Cell. Mol. Biol. 44 (1998), 109-115.

[41] R. Mendelsohn, E.P. Paschalis and A.L. Boskey, Infrared spectroscopy, microscopy, and microscopic imaging of mineralizing tissues: spectra-structure correlations from human iliac crest biopsies, J. Biomed. Optics 4 (1999) 14-21.

[42] L.M. Miller, C.S. Carlson, G.L. Carr and M.R. Chance, A method for examining the chemical basis for bone disease: synchrotron infrared microspectroscopy, Cell. Mol. Biol. 44 (1998), 117-127.

[43] S. Aparicio, S.B. Doty, N.P. Camacho, E.P. Paschalis, L. Spevak, R. Mendelsohn and A.L. Boskey, Optimal methods for processing mineralized tissue for Fourier transform infrared microspectroscopy, Calcif. Tissue Int. 70 (2002), 422-429.

[44] J.A. Timlin, A. Carden, M.D. Morris, J.F. Bonadio, C.E. Hoffler, K. Kozloff and S.A. Goldstein, Spatial distribution of phosphate species in mature and newly generated mammalian bone by hyperspectral Raman imaging, J. Biomed. Optics 4 (1999), 28-34.

[45] A. Carden, R.M. Rajachar, M.D. Morris and D.H. Kohn, Ultrastructural changes accompanying the mechanical deformation of bone tissue: a Raman imaging study, Calcif. Tissue Int. 72 (2003), 166-175.

[46] K. Golcuk, G.S. Mandair, A.F. Callender, N. Sahar, D.H. Kohn and M.D. Morris, Is photobleaching necessary for Raman imaging of bone tissue using a green laser? Biochim. Biophys. Acta 1758 (2006), 868-873.

[47] C.P. Tarnowski, M.A. Ignelzi Jr., W. Wang, J.M. Taboas, S.A. Goldstein and M.D. Morris, Earliest mineral and matrix changes in force-induced musculoskeletal disease as revealed by Raman microspectroscopic imaging, J. Bone Miner. Res. 19 (2004), 64-71.

[48] N.J. Crane, M.D. Morris, M.A. Ignelzi and G. Yu, Raman imaging demonstrates FGF2-induced craniosynthesis in mouse calvaria, J. Biomed. Opt. 10 (2005), 031119.

[49] A.L. Boskey, E. DiCarlo, E. Paschalis, P. West and R. Mendelsohn, Comparison of mineral quality and quantity in iliac crest biopsies from high- and low-turnover osteoporosis: an FTIR microspectroscopic investigation, Osteoporos. Int. 16 (2005), 2031-2038.

[50] D. Faibesh, S.M. Ott and A.L. Boskey, Mineral changes in osteoporosis. A review, Clin. Orthopod. Relat. Res. 443 (2006), 28-38.

[51] A.L. Boskey, M. Goldberg, A. Kulkarni and S. Gomez, Infrared imaging microscopy of bone: Illustrations from a mouse model of Fabry disease, Biochim. Biophys. Acta 1758 (2006), 942-947.

[52] D. Faibesh, A. Gomes, G. Boivin, I. Binderman and A. Boskey, Infrared imaging of calcified tissue in bone biopsies from adults with osteomalacia, Bone 36 (2005), 6-12.

[53] R. Mendelsohn, E.P. Paschalis, P.J. Sherman and A.L. Boskey, IR microscopic imaging of pathological states and fracture healing of bone, Appl. Spectrosc. 54 (2000), 1183-1191.

[54] E.P. Paschalis, K. Verdelis, S.B. Doty, A.L. Boskey, R. Mendelsohn and M. Yamauchi, Spectroscopic characterization of collagen cross-links in bone, J. Bone Miner. Res. 16 (2001), 1821-1828. 
[55] E.P. Paschalis, R. Recker, E. DiCarlo, S.B. Doty, E. Atti and A.L. Boskey, Distribution of collagen cross-links in normal human trabecular bone, J. Bone Miner. Res. 18 (2003), 1942-1946.

[56] E.P. Paschalis, E. Shane, G. Lyritis, G. Skarantavos, R. Mendelsohn and A.L. Boskey, Bone fragility and collagen cross links, J. Bone Miner. Res. 19 (2004), 2000-2004.

[57] E.P. Paschalis, E.V. Glass, D.W. Donley and E.F. Eriksen, Bone mineral and collagen quality in iliac crest biopsies of patients given teriparatide: new results from the fracture prevention trial, J. Clin. Endocrinol. Metab. 90 (2005), 46444649.

[58] E.P. Paschalis, A.L. Boskey, M. Kassem and E.F. Eriksen, Effect on hormone replacement therapy on bone quality in early postmenopausal woman, J. Bone Miner. Res. 18 (2003), 955-959.

[59] H. Ouyang, P.J. Sherman, E.P. Paschalis, A.L. Boskey and R. Mendelsohn, Fourier transform infrared microscopic imaging: effects of estrogen and estrogen deficiency on fracture healing in rat femurs, Appl. Spectrosc. 58 (2004), 1-9.

[60] E. Atti, S. Gomez, S.M. Wahl, R. Mendelsohn, E. Paschalis and A.L. Boskey, Effects of transforming growth factor- $\beta$ deficiency on bone development: a Fourier transform-infrared imaging analysis, Bone 31 (2002), 675-684.

[61] A.L. Boskey, L. Spevak, E. Paschalis, S.B. Doty and M.D. McKeen, Osteopontin deficiency increases mineral content and mineral crystallinity in mouse bone, Calcif. Tissue Int. 71 (2002), 145-154.

[62] H.C. Anderson, J.B. Sipe, L. Hessle, R. Dhanyamraju, E. Atti, N.P. Camacho and J.L. Millan, Impaired calcification around matrix vesicles of growth plate and bone in alkaline phosphatase-deficient mice, Am. J. Pathol. 164 (2004), 841-847.

[63] Y. Ling, H.F. Rios, E.R. Myers, Y. Lu, J.Q. Feng and A.L. Boskey, DMP1 depletion decreases bone mineralization in vivo: an FTIR imaging analysis, J. Bone Miner. Res. 20 (2005), 2169-2177.

[64] H. Ouyang, E.P. Paschalis, W.E. Majo, A.L. Boskey and R. Mendelsohn, Infrared microscopic imaging of bone: spatial distribution of $\mathrm{CO}_{3}^{2-}$, J. Bone Miner. Res. 16 (2001), 893-900.

[65] M.E. Ruppel, D.B. Burr and L.M. Miller, Chemical makeup of microdamaged bone differs from undamaged bone, Bone 39 (2006), 318-324.

[66] J.A. Timlin, A. Carden, M.D. Morris, R.M. Rajachar and D.H. Kohn, Raman spectroscopic imaging markers for fatiguerelated microdamage in bovine bone, Anal. Chem. 72 (2000), 2229-2236.

[67] P. Spencer, Y. Wang, J.L. Katz and A. Misra, Physicochemical interactions at the dentin/adhesive interface using FTIR chemical imaging, J. Biomed. Opt. 10 (2005), 031104.

[68] K. Verdelis, M.A. Crenshaw, E.P. Paschalis, S. Doty, A. Atti and A.L. Boskey, Spectroscopic imaging of mineral maturation in bovine dentin, J. Dent. Res. 82 (2003), 697-702.

[69] A.C. Ko, L.P. Choo-Smith, M. Hewko, L. Leonardi, M.G. Sowa, C.C. Dong, P. Williams and B. Cleghorn, Ex vivo detection and characterization of early dental caries by optical coherence tomography and Raman spectroscopy, J. Biomed. Opt. 10 (2005), 031118.

[70] P. Garidel, Insights in the biochemical composition of skin as investigated by micro infrared spectroscopic imaging, Phys. Chem. Chem. Phys. 5 (2003), 2673-2679.

[71] G.W. Lucassen, P.J. Caspers and G.J. Puppels, In vivo infrared and Raman spectroscopy of stratum corneum, SPIE 3257 (1998), 52-60.

[72] R. Mendelsohn, C.R. Flach and D.J. Moore, Determination of molecular conformation and permeation in skin via IR spectroscopy, microscopy and imaging, Biochim. Biophys. Acta 1758 (2006), 923-933.

[73] R. Mendelsohn, M.E. Rerek and D.J. Moore, Infrared spectroscopy and microscopic imaging of stratum corneum models and skin, Phys. Chem. Chem. Phys. 2 (2000), 4651-4657.

[74] R. Mendelsohn, H.C. Chen, M.E. Rerek and D.J. Moore, Infrared microscopic imaging maps the spatial distribution of exogenous molecules in skin, J. Biomed. Opt. 8 (2003), 185-190.

[75] C. Xiao, D.J. Moore, C.R. Flach and R. Mendelsohn, Permeation of dimyristoylphosphatidylcholine into skin - structural and spatial information from IR and Raman microscopic imaging, Vib. Spectrosc. 38 (2005), 151-158.

[76] C. Xiao, D.J. Moore, M.E. Rerek, C.R. Flach and R. Mendelsohn, Feasibility of tracking phospholipid permeation from IR and Raman microscopic imaging, J. Invest. Dermatol. 124 (2005), 622-632.

[77] G. Zhang, D.J. Moore, R. Mendelsohn and C.R. Flach, Vibrational microspectroscopy and imaging of molecular composition and structure during human corneocyte maturation, J. Invest. Dermatol. 126 (2006), 1088-1094.

[78] D. Bommannan, R.O. Potts and R.H. Guy, Examination of stratum corneum barrier function in vivo by infrared spectroscopy, J. Invest. Dermatol. 95 (1990), 403-408.

[79] R. Bhargava and I.W. Levin, Gram-Schmidt orthogonalization for rapid reconstruction of Fourier transform infrared spectroscopic imaging data, Appl. Spectrosc. 58 (2004), 995-1000.

[80] C. Xiao, C.R. Flach, C. Marcott and R. Mendelsohn, Uncertainties in depth determination and comparison of multivariate with univariate analysis in confocal Raman studies of a laminated polymer and skin, Appl. Spectrosc. 58 (2004), 382-389.

[81] P.J. Caspers, G.W. Lucassen, E.A. Carter, H.A. Bruining and G.J. Puppels, In vivo confocal Raman microspectroscopy of the skin: noninvasive determination of molecular concentration profiles, J. Invest. Dermatol. 116 (2001), 434-442.

[82] P.J. Caspers, G.W. Lucassen, H.A. Bruining and G.J. Puppels, Automated depth-scanning confocal Raman microspec- 
trometer for rapid in vivo determination of water concentration profiles in human skin, J. Raman Spectrosc. 31 (2000), 813-818.

[83] P.J. Caspers, G.W. Lucassen and G.J. Puppels, Combined in vivo confocal Raman spectroscopy and confocal microscopy of human skin, Biophys. J. 85 (2003), 572-580.

[84] A. Percot and M. Lafleur, Direct observation of domains in model stratum corneum lipid mixtures by Raman microspectroscopy, Biophys. J. 81 (2001), 2144-2153.

[85] L. Knudsen, C.K. Johansson, P.A. Philipsen, M. Gniadecka and H.C. Wulf, Natural variations and reproducibility of in vivo near-infrared Fourier transform Raman spectroscopy of normal human skin, J. Raman Spectrosc. 33 (2002), 574-579.

[86] A. Tfalyli, O. Piot, A. Durlach, P. Bernard and M. Manfait, Discriminating nevus and melanoma on paraffin-embedded skin biopsies using FTIR microspectroscopy, Biochim. Biophys. Acta 1724 (2005), 262-269.

[87] P. Lasch and D. Naumann, FT-IR microspectroscopic imaging of human carcinoma thin sections based on pattern recognition techniques, Cell. Mol. Biol. 44 (1998), 189-202.

[88] M. Gniadecka, P.A. Philipsen, S. Sigurdsson, S. Wessel, O.F. Nielsen, D.H. Christensen, J. Hercogova, K. Rossen, H.K. Thomsen, R. Gniadecki, L.K. Hansen and H.C. Wulf, Melanoma diagnosis by Raman spectroscopy and neural networks: structure alteration in proteins and lipids in intact cancer tissue, J. Invest. Dermatol. 122 (2004), 443-449.

[89] A. Nijssen, T.C. Bakker Schut, F. Heule, P.J. Caspers, D.P. Hayes, M.H.A. Neumann and G.J. Puppels, Discriminating basal cell carcinoma from its surrounding tissue by Raman spectroscopy, J. Invest. Dermatol. 119 (2002), 64-69.

[90] Z. Huang, H. Lui, X.K. Chen, A. Alajlan, D.I. McLean and H. Zeng, Raman spectroscopy of in vivo cutaneous melanin, J. Biomed. Opt. 9 (2004), 1198-1205.

[91] P. Dumas and L. Miller, The use of synchrotron infrared microspectroscopy in biological and biochemical investigations, Vib. Spectrosc. 32 (2003), 3-21.

[92] K.L. Chan, S.G. Kazarian, A. Mavraki and D.R. Williams, Fourier transform infrared imaging of human hair with a high spatial resolution without the use of a synchrotron, Appl. Spectrosc. 59 (2005), 149-155.

[93] E.N. Lewis, A.M. Gorbach, C. Marcott and I.W. Levin, High-fidelity Fourier transform-infrared spectroscopic imaging of primate brain tissue, Appl. Spec. $\mathbf{5 0}$ (1996), 263.

[94] E.N. Lewis, L.H. Kidder, I.W. Levin, V.F. Kalasinski, J.P. Hanig and D.S. Lester, Applications of Fourier transform infrared imaging microscopy in neurotoxicity, Ann. N. Y. Acad. Sc. 820 (1997), 234-246.

[95] D.S. Lester, L.H. Kidder, I.W. Levin and E.N. Lewis, Infrared microspectroscopic imaging of the cerebellum of normal and cytarabine treated rats, Cell. Mol. Biol. 44 (1998), 29-38.

[96] L.H. Kidder, P. Colarusso, S.A. Stewart, I.W. Levin, N.A. Appel, D.S. Lester, P.G. Pentchev and E.N. Lewis, Infrared spectroscopic imaging of the biochemical modifications induced in the cerebellum of the Niemann-Pick type C mouse, J. Biomed. Optics 4 (1999), 7-13.

[97] S.M. LeVine and D.L. Wetzel, Chemical analysis of multiple sclerosis lesions by FTIR microspectroscopy, Free Radic. Biol. Med. 25 (1998), 33-41.

[98] L.P. Choo, D.L. Wetzel, W.C. Halliday, M. Jackson, S.M. LeVine and H.H. Mantsch, In situ characterization of betaamyloid in Alzheimer's diseased tissue by synchrotron Fourier transform infrared microspectroscopy, Biophys. J. 71 (1996), 1672-1679.

[99] L.M. Miller, Q. Wang, T.P. Telivala, R.J. Smith, A. Lanzirotti and J. Miklossy, Synchrotron-based infrared and x-ray imaging shows focalized accumulation of $\mathrm{Cu}$ and $\mathrm{Zn}$ co-localized with $\beta$-amyloid deposits in Alzheimer's disease, $J$. Struct. Biology 155 (2006), 30-37.

[100] J. Kneipp, P. Lasch, E. Baldauf, M. Beekes and D. Naumann, Detection of pathological molecular alterations in scrapieinfected hamster brain by Fourier transform infrared spectroscopy, Biochim. Biophys. Acta 1501 (2000), 189-199.

[101] J. Kneipp, M. Beekes, P. Lasch and D. Naumann, Molecular changes of preclinical scrapie can be detected by infrared spectroscopy, J. Neurosc. 22 (2002), 2989-2997.

[102] J. Kneipp, L.M. Miller, M. Joncic, M. Kittel, P. Lasch, M. Beekes and D. Naumann, In situ identification of protein structural changes in prion-infected tissue, Biochim. Biophys. Acta 1639 (2003), 152-158.

[103] J. Kneipp, L.M. Miller, S. Spassov, F. Sokolowski, P. Lasch, M. Beekes and D. Naumann, Scrapie-infected cells, isolated prions, and recombinant prion protein: a comparative study, Biopolymers 74 (2004), 163-167.

[104] A. Kretlow, Q. Wang, J. Kneipp, P. Lasch, M. Beekes, L. Miller and D. Naumann, FTIR microspectroscopy of prioninfected nervous tissue, Biochim. Biophys. Acta 1758 (2006), 948-959.

[105] S. Koljenovic, L.P. Choo-Smith, T.C. Bakker Schut, J.M. Kros, H.J. van den Berge and G.J. Puppels, Discriminating vital tumor from necrotic tissue in human glioblastoma tissue samples by Raman spectroscopy, Lab. Invest. 82 (2002), $1265-1277$.

[106] S. Koljenovic, T. Bakker Schut, A. Vincent, J.M. Kros and G.J. Puppels, Detection of meningeoma in dura mater by Raman spectroscopy, Anal. Chem. 77 (2005), 7958-7965.

[107] C. Krafft, S.B. Sobottka, G. Schackert and R. Salzer, Analysis of human brain tissue, brain tumors and tumor cells by infrared spectroscopic mapping, Analyst. 129 (2004), 921-925. 
[108] C. Krafft, S.B. Sobottka, G. Schackert and R. Salzer, Near infrared Raman spectroscopic mapping of native brain tissue and intracranial tumors, Analyst. 130 (2005), 1070-1077.

[109] C. Krafft, K. Thümmler, S.B. Sobottka, G. Schackert and R. Salzer, Classification of malignant gliomas by infrared spectroscopy and linear discriminant analysis, Biopolymers 82 (2006), 301-305.

[110] G. Steiner, A. Shaw, L.P. Choo-Smith, M.H. Abuid, G. Schackert, S. Sobottka, W. Steller, R. Salzer and H.H. Mantsch, Distinguishing and grading human gliomas by IR spectroscopy, Biopolymers 76 (2003), 464-471.

[111] C. Beleites, G. Steiner, M.G. Sowa, M.G. Baumgartner, S. Sobottka, G. Schackert and R. Salzer, Classification of human gliomas by infrared imaging spectroscopy and chemometric image processing, Vib. Spectrosc. 38 (2005), 143-149.

[112] C. Krafft, S.B. Sobottka, G. Schackert and R. Salzer, Classification of malignant gliomas by infrared spectroscopic imaging and linear discriminant analysis, Anal. Bioanal. Chem. DOI 10.1007/s00216-006-0892-5.

[113] C. Krafft, L. Shapoval, S.B. Sobottka, K.D. Geiger, G. Schackert and R. Salzer, Identification of primary tumors of brain metastases by SIMCA classification of IR spectroscopic images, Biochim. Biophys. Acta 1758 (2006), 883-891.

[114] C. Krafft, L. Shapoval, S.B. Sobottka, G. Schackert and R. Salzer, Identification of primary tumors of brain metastases by IR spectroscopic imaging and linear discriminant analysis, Technol. Cancer Res. Treatm. 5 (2006), 291-298.

[115] C. Krafft, S.B. Sobottka, G. Schackert and R. Salzer, Raman and infrared spectroscopic mapping of human primary intracranial tumors: a comparative study, J. Raman Spectros. 37 (2006), 367-375.

[116] S. Koljenovic, T.C. Bakker Schut, R. Wolthuis, B. de Jong, L. Santos, P.J. Caspers, J.M. Kros and G.J. Puppels, Tissue characterization using high wave number Raman spectroscopy, J. Biomed. Optics 10 (2005), 031116.

[117] K.R. Bambery, E. Schültke, B.R. Wood, S.T. Rigley MacDonald, K. Ataelmannan, R.W. Griebel, B.H.J. Juurlink and D. McNaughton, A Fourier transform infrared microspectroscopic imaging investigation into an animal model exhibiting glioblastoma multiforme, Biochim. Biophys. Acta 1758 (2006), 900-907.

[118] N. Amharref, A. Beljebbar, S. Dukic, L. Venteo, L. Schneider, M. Pluot, R. Vistelle and M. Manfait, Brain tissue characterization by infrared imaging in a rat glioma model, Biochim. Biophys. Acta 1758 (2006), 892-899.

[119] C. Conti, E. Giorgini, T. Pieramici, C. Rubini and G. Tosi, FT-IR microscopy imaging on oral cavity tumors II, $J$. Molecular Structure 744-747 (2005), 187-193.

[120] T. Yamada, N. Miyoshi, T. Ogawa, K. Akao, M. Fukada, T. Ogasawara, Y. Kitagawa and K. Sano, Observation of molecular changes of a necrotic tissue from a murine carcinoma by Fourier-transform infrared microspectroscopy, Clinical Cancer Research 8 (2002), 2010-2014.

[121] C.P. Schultz, K.Z. Kerr and H.H. Mantsch, In situ infrared histopathology of keratinization in human oral/oropharyngeal squamous cell carcinoma, Oncol. Res. 10 (1998), 277-286.

[122] C.P. Schultz and H.H. Mantsch, Biochemical imaging and 2D classification of keratin pearl structures in oral squamous cell carcinoma, Cell. Mol. Biol. 44 (1998), 203-210.

[123] Z. Huang, H. Lui, D.I. McLean, M. Korbelik and H. Zeng, Raman spectroscopy in combination with background nearinfrared autofluorescence enhances the in vivo assessment of malignant tissues, Photochem. Photobiol. 81 (2005), 12191226.

[124] D.P. Lau, Z. Huang, H. Lui, C.S. Man, K. Berean, M.D. Morrison and H. Zeng, Raman spectroscopy for optical diagnosis in normal and cancerous tissue of the nasopharynx - preliminary findings, Laser Surg. Med. 32 (2003), 210-214.

[125] P. Lasch, W. Haensch, E.N. Lewis, L.H. Kidder and D. Naumann, Characterization of colorectal adenocarcinoma sections by spatially resolved FTIR microspectroscopy, Appl. Spectrosc. 48 (2002), 1-10.

[126] P. Lasch, W. Haensch, D. Naumann and M. Diem, Imaging of colorectal adenocarcinoma using FTIR microspectroscopy and cluster analysis, Biochim. Biophys. Acta 1688 (2004), 176-186.

[127] N. Stone, C. Kendall, N. Shephard, P. Crow and H. Barr, Near-infrared Raman spectroscopy for the classification of epithelial pre-cancers and cancers, J. Raman Spectrosc. 33 (2002), 564-573.

[128] C. Kendall, N. Stone, N. Shephard, K. Geboes, B. Warren, R. Bennet and H. Barr, Raman spectroscopy, a potential tool for the objective identification and classification of neoplasia in Barrett's oesophagus, J. Pathol. 200 (2003), $602-609$.

[129] G. Shetty, C. Kendall, N. Shephard, N. Stone and H. Barr, Raman spectroscopy: elucidation of biochemical changes in carcinogenesis of oesophagus, Br. J. Cancer 94 (2006), 1460-1464.

[130] D.R. Kodali, D.M. Small, J. Powell and K. Krishnan, Infrared micro-imaging of atherosclerotic arteries, Appl. Spectrosc. 45 (1991), 1310-1317.

[131] R. Manoharan, J.J. Baraga, R.P. Rava, R.R. Dasari, M. Fitzmaurice and M.S. Feld, Biochemical analysis and mapping of atherosclerotic human artery using FTIR microspectroscopy, Atherosclerosis 103 (1993), 181-193.

[132] H.H.T. Hsu, N.C. Camacho, O. Tawfik and F. Sun, Induction of calcification in rabbit aortas by high cholesterol diets: roles of calcifiable vesicles in dystrophic calcification, Atherosclerosis 161 (2002), 85-94.

[133] C. Li, D. Ebenstein, C. Xu, J. Chapman, D. Saloner, J. Rapp and L. Pruitt, Biochemical characterization of atherosclerotic plaque constituents using FTIR spectroscopy and histology, J. Biomed. Mater. Res. A 64 (2003), 197-206.

[134] C.S. Colley, S.G. Kazarian, P.D. Weinberg and M.J. Lever, Spectroscopic imaging of arteries and atherosclerotic plaques, Biopolymers 74 (2004), 328-335.

[135] F. Bonnier, S. Rubin, L. Venteo, C.M. Krishna, M. Pluot, B. Baehrel, M. Manfait and G.D. Sockalingum, In-vitro analysis 
of normal and aneurismal human ascending aortic tissues using FT-IR microspectroscopy, Biochim. Biophys. Acta 1758 (2006), 968-973.

[136] S.W.E. van de Poll, T.J. Romer, G.J. Puppels and A. van der Laarse, Imaging of atherosclerosis. Raman spectroscopy of atherosclerosis, J. Cardiovasc. Risk 9 (2002), 255-261.

[137] S.W.E. van de Poll, T.C. Bakker Schut, A. van der Laarse and G.J. Puppels, In situ investigation of the chemical composition of ceroid in human atherosclerosis by Raman spectroscopy, J. Raman Spectrosc. 33 (2002), 544-551.

[138] S.W.E. van de Poll, D.J.M. Delsing, J.W. Jukema, H.M.G. Princen, L.M. Havekes, G.J. Puppels and A. van der Laarse, Raman spectroscopic investigation of atorvastatin, amlodipine, and both on atherosclerotic plaque development in APOE*3 Leiden transgenic mice, Atherosclerosis 164 (2002), 65-71.

[139] S.W.E. van de Poll, K. Kastelijn, T.C. Bakker Schut, G. Pasterkamp, G.J. Puppels and A. van der Laarse, On-line detection of cholesterol and calcification by catheter based Raman spectroscopy in human atherosclerotic plaque ex vivo, Heart 89 (2003), 1078-1082.

[140] L.H. Kidder, V.F. Kalasinsky, J.L. Luke, I.W. Levin and E.N. Lewis, Visualization of silicone gel in human breast tissues using new infrared imaging spectroscopy, Nat. Med. 3 (1997), 235-237.

[141] S.R. Ali, F.B. Johnson, J.L. Luke and V.F. Kalasinsky, Characterization of silicone breast implant biopsies by Fourier transform infrared mapping, Cell. Mol. Biol. 44 (1998), 75-80.

[142] H. Fabian, P. Lasch, M. Boese and W. Haensch, Mid-IR microspectroscopic imaging of breast tumor tissue section, Biopolymers 67 (2002), 354-357.

[143] H. Fabian, P. Lasch, M. Boese and W. Haensch, Infrared microspectroscopic imaging of benign breast tumor tissue sections, J. Mol. Structure 661-662 (2003), 411-417.

[144] H. Fabian, N.A.N. Thi, M. Eiden, P. Lasch, J. Schmidt and D. Naumann, Diagnosing benign and malignant lesions in breast tissue sections by using IR microspectroscopy, Biochim. Biophys. Acta 178 (2006), 874-882.

[145] K.E. Shafer-Peltier, A.S. Haka, M. Fitzmaurice, J. Crowe, J. Myles, R.R. Dasari and M.S. Feld, Raman microspectroscopic model of human breast tissue: implications for breast cancer diagnosis in vivo, J. Raman Spectrosc. 33 (2002), 552-563.

[146] J. Smith, C. Kendall, A. Sammon, J. Christie-Brown and N. Stone, Raman spectral mapping in the assessment of axillary lymph nodes in breast cancer, Technol. Cancer Res. Treat. 2 (2003), 327-332.

[147] J.T. Motz, S.J. Gandhi, O.R. Scepanovic, A.S. Haka, J.R. Kramer, R.R. Dasari and M.S. Feld, Real time Raman system for in vivo disease diagnosis, J. Biomed. Optics 10 (2005), 031113.

[148] M.J. Li, H.S. Hsu, R.C. Liang and S.Y. Lin, Infrared microspectroscopic detection of epithelial and stromal growth in the human benign prostatic hyperplasia, Ultrastruct. Pathol. 26 (2002), 365-370.

[149] D.C. Fernandez, R. Bhargava, S.M. Hewitt and I.W. Levin, Infrared spectroscopic imaging for histopathologic recognition, Nat. Biotechnol. 23 (2005), 469-474.

[150] R. Bhargava, D.C. Fernandez, S.M. Hewitt and I.W. Levin, High throughput assessment of cells and tissues: Bayesian classification of spectral metrics from infrared vibrational spectroscopic imaging data, Biochim. Biophys. Acta 1758 (2006), 830-845.

[151] J. Einenkel, W. Steller, U.D. Braumann, L.C. Horn and C. Krafft, Selection bias for receiver operating curves, Nat. Biotechnol. (in press).

[152] E. Gazi, J. Dwyer, N. Lockyer, P. Gardner, J.C. Vickerman, J. Miyan, C.A. Hart, M. Brown, J.H. Shanks and N. Clarke, The combined application of FTIR microspectroscopy and ToF-SIMS imaging in the study of prostate cancer, Faraday Discuss. 126 (2004), 41-59.

[153] B.W. de Jong, C.A. de Gouveia Brazao, H. Stoop, K.P Wolffenbuttel, J.W. Oosterhuis, G.J. Puppels, R.F. Weber, L.H. Looijenga and D.J. Kok, Raman spectroscopic analysis identifies testicular microlithiasis as intratubular hydroxyapatite, J. Urol. 171 (2002), 92-96.

[154] M.C. Prieto, P. Matousek, M. Towrie, A.W. Parker, M. Wright, A.W. Ritchie and N. Stone, Use of picosecond Kerr-gated Raman spectroscopy to suppress signals from both surface and deep layers in bladder and prostate tissue, J. Biomed. Opt. 10 (2005), 44006.

[155] K. Potter, L.H. Kidder, I.W. Levin, E.N. Lewis and R.G.S. Spencer, Imaging collagen and proteoglycan in cartilage sections using Fourier transform infrared spectral imaging, Arthritis \& Rheumatism 44 (2001), 846-855.

[156] N.P. Camacho, P. West, P.A. Torzilli and R. Mendelsohn, FTIR microscopic imaging of collagen and proteoglycan in bovine cartilage, Biopolymers 62 (2001), 1-8.

[157] N.P. Camacho, P. West, M.H. Griffith, R.F. Warren and C. Hidaka, FTIR imaging spectroscopy of genetically modified bovine chondrocytes, Mater. Sci. Eng. C17 (2001), 3-9.

[158] M. Kim, X. Bi, W.E. Horton, R.G. Spencer and N.P. Camacho, Fourier transform infrared imaging spectroscopy analysis of tissue engineered cartilage: histologic and biochemical correlations, J. Biomed. Opt. 10 (2005), 031105.

[159] X. Bi, X. Yang, M.P.G. Bostrom and N.P. Camacho, Fourier transform infrared imaging spectroscopy investigations in the pathogenesis and repair of cartilage, Biochim. Biophys. Acta 1758 (2006), 934-941. 
[160] X. Bi, G. Li, S.B. Doty and N.P. Camacho, A novel method for determination of collagen orientation in cartilage by Fourier transform infrared imaging spectroscopy, Osteoarthritis Cartilage 13 (2005), 1050-1058.

[161] P.A. West, P.A. Torzilli, C. Chen, P. Lin and N.P. Camacho, Fourier transform infrared imaging spectroscopy analysis of collagenase-induced cartilage degradation, J. Biomed. Opt. 10 (2005), 14015.

[162] P.T.T. Wong, S. Lacelle, M. Sentermann and F.K.M. Fung, Characterization of the exfoliated cells and tissues from the human endo and ecto-cervix by FTIR and ATR-FTIR spectroscopy, Biospectrosc. 1 (1995), 357-364.

[163] S.R. Lowry, The analysis of exfoliated cervical cells by infrared microscopy, Cell. Mol. Biol. 44 (1998), 169-177.

[164] L. Chiriboga, P. Xie, H. Yee, D. Zarou, D. Zakim and M. Diem, Infrared spectroscopy of human tissue IV. Detection of dysplastic and neoplastic changes of human cervical tissue via infrared microscopy, Cell. Mol. Biol. 44 (1998), 219-229.

[165] J.I. Chang, Y.B. Huang, P.C. Wu, C.C. Chen, S.C. Huang and Y.H. Tsai, Characterization of human cervical precancerous tissue through the Fourier transform infrared microscopy with mapping method, Gynecol. Oncol. 91 (2003), 577-583.

[166] B.R. Wood, L. Chiriboga, H. Yee, M.A. Quinn, D. McNaughton and M. Diem, Fourier transform infrared spectral mapping of the cervical transformation zone and dysplastic epithelium, Gynecol. Oncol. 93 (2004), 59-68.

[167] W. Steller, J. Einenkel, L.C. Horn, U.D. Braumann, H. Binder, R. Salzer and C. Krafft, Delimitation of squamous cell cervical carcinoma using infrared microspectroscopic imaging, Anal. Bioanal. Chem. 384 (2006), 145-154.

[168] Z. Huang, A. McWilliams, H. Lur, D.I. McLean, S. Lam and H. Zeng, Near infrared Raman spectroscopy for optical diagnosis of lung cancer, Int. J. Cancer 107 (2003), 1047-1052.

[169] S. Kaminaka, T. Ito, H. Yamazaki, E. Kohda and H. Hamaguchi, Near-infrared multichannel Raman spectroscopy toward real-time in vivo cancer diagnosis, J. Raman Spectrosc. 33 (2002), 498-502.

[170] S. Koljenovic, T.C. Bakker Schut, J.P. van Meerbeeck, A.P. Maat, S.A. Burgers, P.E. Zondervan, J.M. Kros and G.J. Puppels, Raman microspectroscopic mapping studies of human bronchial tissue, J. Biomed. Opt. 9 (2004), 1187-1197.

[171] K. Yano, S. Ohoshima, Y. Gotou, K. Kumaido, T. Moriguchi and H. Katayama, Direct measurement of human lung cancerous and noncancerous tissues by Fourier transform infrared microscopy: can an infrared microscope be used as a clinical tool? Anal. Biochem. 287 (2000), 218-225.

[172] Y. Yang, J. Sole-Suso, G.D. Sockalingum, G. Kegelaer, M. Manfait and A.J. El Haj, Study of tumor cell invasion by Fourier transform infrared microspectroscopy, Biopolymers 78 (2005), 311-317.

[173] P.S. Bernstein, D.Y. Zhao, M. Sharifzadeh, I.V. Ermakov and W. Gellermann, Resonance Raman measurement of macular carotenoids in the living human eye, Arch. Biochem. Biophys. 430 (2004), 163-169.

[174] W. Gellermann, I.V. Ermakov, R.W. McClane and P.S. Bernstein, Raman imaging of human macular pigments, Opt. Lett. 27 (2002), 833-835.

[175] J. Sebag, Seeing the invisible: the challenge of imaging vitreos, J. Biomed. Opt. 9 (2004), 38-46.

[176] A. Katz, E.F. Kruger, G. Minko, C.H. Liu, R.B. Rosen and R.R. Alfano, Detection of glutamate in the eye by Raman spectroscopy, J. Biomed. Opt. 8 (2003), 167-172.

[177] N.M. Sijtsema, J.J. Duindam, G.J. Puppels, C. Otto and J. Greve, Imaging with extrinsic Raman labels, Appl. Spectrosc. 50 (1996), 545-551.

[178] K.Z. Liu, A. Man, R.A. Shaw, B. Liang, Z. Xu and Y. Gong, Molecular determination of liver fibrosis by synchrotron infrared microspectroscopy, Biochem. Biophys. Acta 1758 (2006), 960-967.

[179] M. Diem, L. Chiriboga and H. Yee, Infrared spectroscopy of human cells and tissue. VIII. Strategies for analysis of infrared tissue mapping data and applications to liver tissue, Biopolymers 57 (2000), 282-290.

[180] M. Jackson, B. Ramjiawan, M. Hewko and H.H. Mantsch, Infrared microscopic functional group mapping and spectral clustering analysis of hypercholesterolemic rabbit liver, Cell. Mol. Biol. 44 (1998), 89-98.

[181] K.M. Gough, D. Zelinski, R. Wiens, M. Rak and I.M. Dixon, Fourier transform infrared evaluation of microscopic scarring in the cardiomyopathic heart: effect of chronic AT1 suppression, Anal. Biochem. 316 (2003), 232-242.

[182] K.Z. Liu, I.M. Dixon and H.H. Mantsch, Distribution of collagen distribution in cardiomyopathic hamster hearts determined by infrared microscopy, Cardiovasc. Pathol. 8 (1999), 41-47.

[183] C. Krafft, R. Salzer, G. Soff and M. Meyer-Hermann, Identification of B and T cells in human spleen sections by infrared microspectroscopic imaging, Cytometry A 64A (2003), 53-61. 


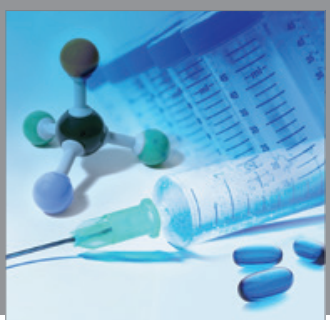

International Journal of

Medicinal Chemistry



Carbohydrate Chemistry

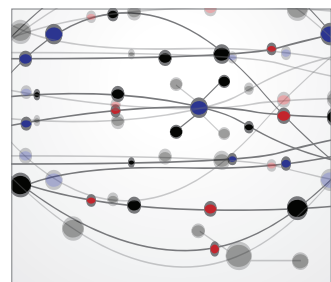

The Scientific World Journal
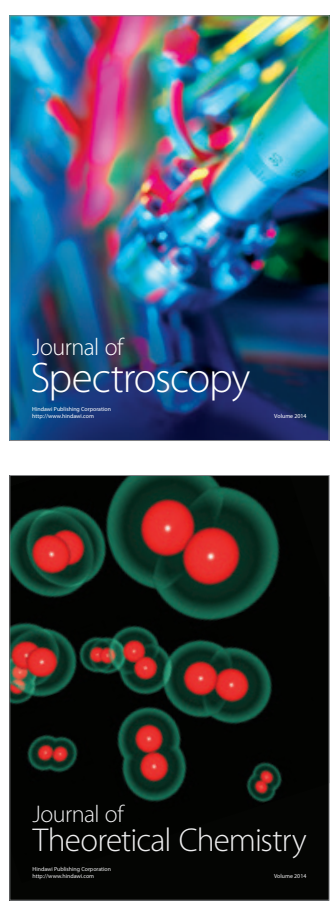


Submit your manuscripts at

http://www.hindawi.com
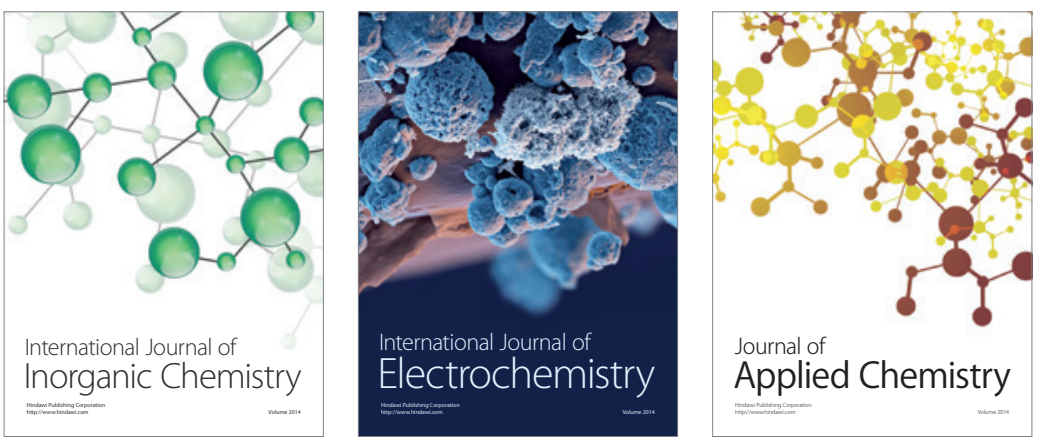

Journal of

Applied Chemistry
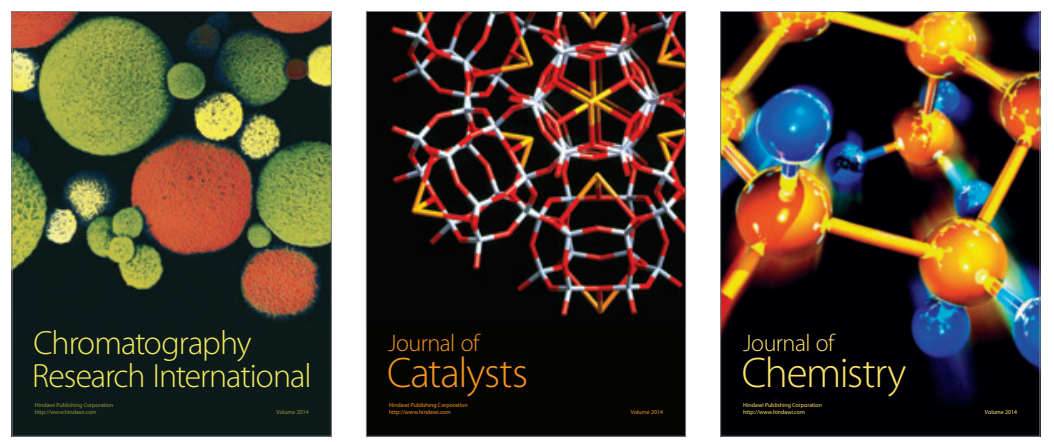
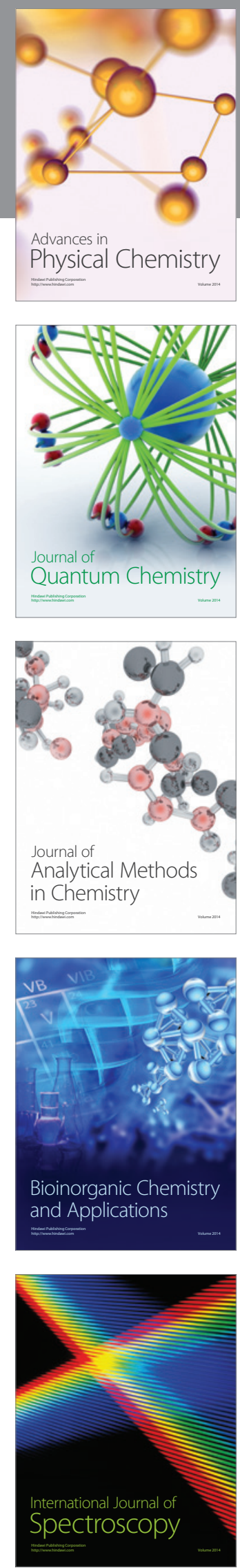